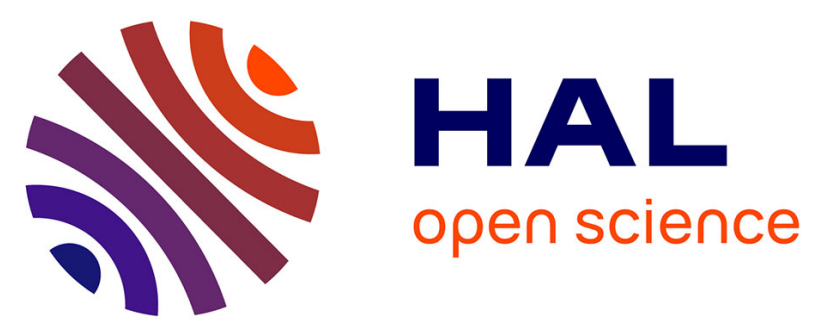

\title{
Combination of biocompatible hydrogel precursors to apatitic calcium phosphate cements (CPCs): Influence of the in situ hydrogel reticulation on the CPC properties
}

Silvia Stella Ramirez Caballero, Daniel Ferri-angulo, Romain Debret, Fabien Granier, Sébastien Marie, François-Xavier Lefèvre, Jean-Michel Bouler, Christelle Despas, Jérôme Sohier, Bruno Bujoli

\section{To cite this version:}

Silvia Stella Ramirez Caballero, Daniel Ferri-angulo, Romain Debret, Fabien Granier, Sébastien Marie, et al.. Combination of biocompatible hydrogel precursors to apatitic calcium phosphate cements (CPCs): Influence of the in situ hydrogel reticulation on the CPC properties. Journal of Biomedical Materials Research Part B: Applied Biomaterials, In press, 10.1002/jbm.b.34685 . hal-03008332

\section{HAL Id: hal-03008332 \\ https://hal.science/hal-03008332}

Submitted on 16 Nov 2020

HAL is a multi-disciplinary open access archive for the deposit and dissemination of scientific research documents, whether they are published or not. The documents may come from teaching and research institutions in France or abroad, or from public or private research centers.
L'archive ouverte pluridisciplinaire HAL, est destinée au dépôt et à la diffusion de documents scientifiques de niveau recherche, publiés ou non, émanant des établissements d'enseignement et de recherche français ou étrangers, des laboratoires publics ou privés.

\section{(ㄷ)(1) $\$$}

Distributed under a Creative Commons Attribution - NonCommerciall 4.0 International 


\title{
Combination of biocompatible hydrogel precursors to apatitic calcium phosphate cements (CPCs): influence of the in situ hydrogel reticulation on the CPC properties.
}

Silvia Stella Ramirez Caballero, ${ }^{\mathrm{a}}$ Daniel Ferri Angulo, ${ }^{\mathrm{b}}$ Romain Debret, ${ }^{\mathrm{c}}$ Fabien Granier, ${ }^{\mathrm{d}}$ Sébastien Marie, ${ }^{\mathrm{d}}$ François-Xavier Lefèvre, ${ }^{\mathrm{e}}$ Jean-Michel Bouler, ${ }^{\mathrm{e}}$ Christelle Despas, ${ }_{\mathrm{f}}^{\mathrm{f}}$ Jérôme Sohier, ${ }^{\mathrm{b}}$ and Bruno Bujoli*e

${ }^{\text {a}}$ Graftys Discovery SA, UFR Sciences et Techniques, Chemin de la Houssinière 2, 44300, Nantes (France), ${ }^{\text {b}}$ Université Lyon, INSA Lyon, UMR 5510 CNRS, MATEIS, 69621 Villeurbanne (France), ' UMR 5305 CNRS, Laboratory of biology tissue and therapeutic engineering LBTI, Lyon, 69367 (France), 'Colcom, Cap Alpha, Avenue de l'Europe, 34830 Clapiers (France), e'Université de Nantes, CNRS, UMR 6230, CEISAM, UFR Sciences et Techniques, 2, rue de la Houssinière, BP 92208, 44322 NANTES Cedex 3 (France), ${ }^{\mathrm{f}}$ NancyUniversité, CNRS, UMR 7564, LCPME, 405 rue de Vandoeuvre, 54600 Villers-lès- Nancy (France)

Email: bruno.bujoli@univ-nantes.fr

\begin{abstract}
In the field of bone regenerative medicine, injectable calcium phosphate cements (CPCs) are used for decades in clinics, as bone void fillers. Most often pre-formed polymers (e.g. hyaluronic acid, collagen, chitosan, cellulose ethers...) are introduced in the CPC formulation to make it injectable and improve its cohesion. Once the cement has hardened, the polymer is simply trapped in the CPC structure and no organic sub-network is present. By contrast, in this work a CPC was combined with organic monomers that reticulated in situ so that a continuous biocompatible 3D polymeric sub-network was formed in the CPC microstructure, resulting in
\end{abstract}


a higher permeability of the $\mathrm{CPC}$ which might allow to accelerate its in vivo degradation. Two options were investigated depending whether the polymer was formed before the apatitic inorganic network or concomitantly. In the former case, conditions were found to reach a suitable rheology for easy injection of the composite. In addition, the in situ formed polymer was shown to strongly affect the size, density and arrangement of the apatite crystals formed during the setting reaction, thereby offering an original route to modulate the microstructure and porosity of apatitic cements.

Key words: apatitic cement; reticulated hydrogel; composite biomaterial; microstructure.

\section{Introduction}

The use of calcium phosphate cements $(\mathrm{CPCs})^{1-3}$ as bone substitutes in clinics is rapidly expanding, in particular in trauma surgery. ${ }^{4-7}$ Similarly to calcium phosphate bioceramics, CPCs show excellent biocompatibility, bioactivity and osteoconductivity, leading to their replacement by bone over a few months, thanks to the natural bone remodeling process. When injectable, they offer the possibility for filling bone voids of any shape, under minimally invasive conditions. ${ }^{8-12}$ In this context, the latest improvements to confer suitable injectability ${ }^{13-}$ ${ }^{16}$ and cohesion ${ }^{17,18}$ to CPCs, and tune their mechanical properties ${ }^{19-22}$ and porosity ${ }^{23-25}$, most often include the introduction of polymer additives in the CPC formulation (e.g. sodium alginate, hyaluronic acid, collagen, polypeptides, chitosan, cellulose ethers... $)^{26-43}$ Interestingly, these polymers solubilized in the intergranular space of the cement paste often contribute to avoid phase separation between the liquid and solid components of the CPC, and provide a suitable rheology for an easy injection through a syringe needle.

In the early stage of the setting reaction of apatitic CPCs, precipitation of apatite crystals occurs quite rapidly in the intergranular space initially occupied by the liquid phase (containing additives or not). The entanglement of these crystals then leads to a hardened material. 
Depending on the nature of the CPC, this reaction starts a few minutes (ca. 2-5 minutes) after mixing the CPC liquid and solid phases and usually ends up after a $10-40$ minutes period. ${ }^{44}$ When a pre-formed polymer (e.g. hyaluronic acid, collagen, chitosan, cellulose ethers...) is present in the CPC formulation, the latter is simply trapped in the CPC structure once the cement has hardened and does not influence that much the cement microstructure since no organic subnetwork is present. In this context, we were interested to investigate whether the introduction of organic monomers that would self-assemble in situ concomitantly or even before the CPC setting process, might influence the microstructure of the hardened CPC. Indeed, the formation a continuous biocompatible 3D polymeric sub-network might result in a higher permeability of the CPC which might allow to accelerate its in vivo degradation. With these considerations in mind, the precursor candidates selected for this study were based on poly(L-lysine) dendrigrafts (DGL) and polyethylene glycol homobifunctionalized with N-hydroxysuccinimide (PEGNHS). PEG is indeed a bio-inert polymer approved by the FDA for several medical applications ${ }^{45}$ while DGL are non-immunogenic dendrimers of low cytotoxicity. ${ }^{46,47}$ When these two products are mixed in aqueous solution, the reticulation process is driven by the reaction of the activated ester end-groups of PEG-NHS with the alpha and epsilon amine groups of DGL which creates a 3D network through the formation of stable amide bonds in physiologic to slightly alkaline conditions ( $\mathrm{pH} 7.2$ to 9 ). ${ }^{48} \mathrm{~N}$-hydroxysuccinimide (NHS) is concomitantly released as a result of this condensation reaction (Figure 1). More importantly, depending on the concentration of the two hydrogel precursors, the crosslinking time in phosphate buffered saline (PBS) can be varied between a few seconds to a few minutes, as well as the mechanical properties of the hydrogels, with a complex modulus ranging from a few to $100 \mathrm{kPa}$. Furthermore, this hydrogel was shown to be non-cytotoxic and to act as a support promoting cellular attachment and proliferation, while being biocompatible and degraded in vivo through phagocytosis by macrophages. ${ }^{48,49}$ As such, it was shown to have great potential to stimulate 
skin wound healing, thus making very attractive its assessment in the context of bone regeneration and repair.

\section{Materials and methods}

\subsection{Chemicals}

Two apatitic calcium phosphate cements (CPCs) were used in this study:

- Graftys ${ }^{\circledR}$ HBS [abbreviated as HBS], obtained from Graftys SA (Aix-en-Provence, France), is a mixture of 78 wt.\% $\alpha$-tricalcium phosphate $(\alpha-\mathrm{TCP})\left(\mathrm{Ca}_{3}\left(\mathrm{PO}_{4}\right)_{2}\right), 5$ wt.\% dicalcium phosphate dihydrate (DCPD) $\left(\mathrm{CaHPO}_{4}, 2 \mathrm{H}_{2} \mathrm{O}\right), 5$ wt.\% monocalcium phosphate monohydrate (MCPM) $\left(\mathrm{Ca}\left(\mathrm{H}_{2} \mathrm{PO}_{4}\right)_{2}, \mathrm{H}_{2} \mathrm{O}\right), 10$ wt.\% calcium-deficient hydroxyapatite (CDA) (Ca10x[ ] $\left.{ }_{x}\left(\mathrm{HPO}_{4}\right) y\left(\mathrm{PO}_{4}\right)_{6-y}(\mathrm{OH})_{2-z}[]_{z}\right), 2$ wt.\% hydroxypropyl methyl cellulose (HPMC). The liquid phase consisted of a 2 or $5 \mathrm{wt} . \% \mathrm{Na}_{2} \mathrm{HPO}_{4}$ aqueous solution (liquid/powder ratio $=0.5 \mathrm{~mL} . \mathrm{g}^{-}$ $1)$.

- A HPMC-free analogue of Graftys ${ }^{\circledR}$ HBS [abbreviated as HBS-0] was especially prepared for this study, under the same conditions except that no HPMC was added to the fabrication process.

A $10 \mathrm{kDa}$ polyethyleneglycol chain end-capped with two N-hydrosuccinimide groups (noted PEG-NHS) was obtained from Sigma-Aldrich (ref 713797, CAS 186020-53-1). A third generation poly(L-lysine) dendrigraft (noted DGL) was obtained from COLCOM and prepared as previously reported. ${ }^{50}$ TFA-L-Lys-NCA being used as monomers for the polymerization process, the synthesis leads to poly-cationic polymers of L-Lysine with protonated amino groups associated with trifluoroacetate (noted TFA) counter-ions after deprotection of the $\varepsilon$ amines of the Lysine units. The last step consisted of an exchange of the TFA counter-ions by chloride, via the addition of a large excess of a sodium chloride aqueous solution. Then the free salts were removed by ultrafiltration using a $5 \mathrm{kDa}$ cut off. Residual TFA was lower than $1 \%$ 
as controlled by ${ }^{19} \mathrm{~F}$ NMR.

\subsection{Preparation of the calcium phosphate cement formulations}

HBS and HBS-0 cement samples were prepared by mixing $5 \mathrm{~g}$ of the powdered preparation with their liquid phase for 1 minute to ensure the homogeneity of the resulting paste before use. For the preparation of the composite, a DGL / PEG-NHS weight ratio of ca. 0.16 was selected for this study. ${ }^{48}$ The required amount of solid PEG-NHS was first dispersed in $5 \mathrm{~g}$ of the HBS0 CPC powder, and the two products were mixed in a mortar, using a pestle. On the other hand, the required amount of DGL powder was dissolved in $2.5 \mathrm{~mL}$ of a $\mathrm{Na}_{2} \mathrm{HPO}_{4}$ aqueous solution (either 2 or $5 \mathrm{wt} . \%$ ). In a final step, the DGL solution was added to the CPC / PEG-NHS powder, and the resulting mixture was mixed in a mortar for 1 minute to obtain a homogeneous paste. The resulting composite were then noted $8 / 50,16 / 100,24 / 150$ or $40 / 250$, where for example 24/150 corresponds to a DGL concentration of $24 \mathrm{mg} \mathrm{mL}^{-1}$ and a PEG-NHS concentration of $150 \mathrm{mg} \mathrm{mL}^{-1}$, with respect to the liquid phase (i.e. the $\mathrm{Na}_{2} \mathrm{HPO}_{4}$ aqueous solution).

To investigate the properties of the different cements prepared in this study (mechanical properties and microstructure), specimens of cylindrical shape (6 $\mathrm{mm}$ in diameter and $12 \mathrm{~mm}$ of length) were prepared by pressing the resulting pastes into Teflon molds using a spatula. The molds containing the paste were immersed in a saline solution (0.9 wt.\% sodium chloride aqueous solution), then incubated in a homothermal oven at $37{ }^{\circ} \mathrm{C}$ for 72 hours or one week, before being polished to obtain flat and parallel faces for the bulk specimens, that were then unmolded.

To investigate whether a 3D-organic network had formed in the different hydrogel-containing cement composites once hardened, decalcification of the samples was performed by immersion of cylindrical cement blocks (diameter: $8 \mathrm{~mm}$; height: $5 \mathrm{~mm}$; hardening time: 1 week) in $30 \mathrm{~mL}$ of a $10 \mathrm{wt} . \%$ aqueous solution of ethylenediaminetetraacetic acid (EDTA) at room temperature for 2 weeks, with a renewal of the EDTA solution every 5 days. At the end of this treatment, 
the samples were immerged successively in water $(10 \mathrm{~mL}, 2$ days $), 95 \%$ ethanol $(30 \mathrm{~mL}, 3$ days) and pure ethanol. The samples were then rinsed in water/acetone mixtures of increasing content in acetone, to end-up with a rinsing with pure acetone. Finally, the samples were dried by applying 12 cycles of rinsing with supercritical carbon dioxide. Similar experiments run with conventional HBS or HBS-0 led to a full dissolution of the corresponding cement blocks, by contrast with the hydrogel-containing composites that in most cases retained their initial shape.

\subsection{Methods}

\subsubsection{SEM experiments}

The measurements were carried out on cylindrical cement blocks allowed to harden for one week (see section 2.2). Then, a $1 \mathrm{~mm}^{2}$ polished cross-section of the samples was obtained using a JEOL cross section polisher SM09010, by applying an argon ion beam accelerated by a voltage from 4.5 to $6 \mathrm{kV}$ perpendicular to the surface of each specimen for 4 to 8 hours. SEM observation of those samples was performed using a Field Emission Gun Scanning Electron Microscope (Jeol 7600F). Images were acquired on a back scattered electron mode with a 8 pA beam current and a $8 \mathrm{kV}$ accelerated voltage.

\subsubsection{Compressive strength measurements}

The measurements were carried out on cylinder-shaped molded samples under wet conditions (hardening time: 72 hours), i.e. immediately after taking the specimens out of the hardening solution (see section 2.2). A TAHD+ texture analyzer was used and the samples were submitted to increasing compression load (displacement of the compressive rig: $1 \mathrm{~mm} \cdot \mathrm{s}^{-1}$ ), the profile of which was recorded until fracture.

\subsubsection{Dynamic mechanical analyses (DMA)}

The dynamics properties of the CPC references, hydrogels and CPC composites were determined using a Dynamic Mechanical Analyser (NETZCH DMA 242E Artemis and DMA 242E, TASC414/4 and CS200LT as controllers) at room temperature. The variation of the 
mechanical phase angle tangent (tan $\delta$ ) versus time was thus recorded, this parameter corresponding to the ratio between the dynamic loss modulus (E") and dynamic storage modulus (E') ( $\left.\tan \delta=\mathrm{E}^{\prime \prime} / \mathrm{E}^{\prime}\right)$. The evolution of $\tan \delta$ is representative of changes in the viscosity of the samples, the higher the $\tan \delta$ value, the greater the viscosity of the materials, and the onset point of the $\tan \delta$ versus time curve (Proteus ${ }^{\circledR}$ software) was thus used to assess the time at which the phase transitions occurred.

In a typical experiment, DGL was dissolved in a 2 or 5 wt. $\% \mathrm{Na}_{2} \mathrm{HPO}_{4}$ aqueous solution (200 $\mu \mathrm{L}$, at different concentration: $8,16,24$ or $40 \mathrm{mg} \mathrm{mL}^{-1}$, respectively). Afterward, this solution was added to the desired crushed solid placed in a $12 \times 6 \mathrm{~mm}$ cupula, i.e. either pure PEG-NHS or PEG-NHS mixed with $400 \mathrm{mg}$ of HBS-0, so that the final concentration of PEG-NHS with respect to the liquid phase was $50,100,150$ or $250 \mathrm{mg} \mathrm{mL}^{-1}$, with a DGL/PEG-NHS ratio of 0.16. The resulting mixture was mixed by hand for approximately $1 \mathrm{~min}$ at room temperature in the cupula. A $8 \times 4 \mathrm{~mm}$ rod connected to the DMA and undergoing a sinusoidal vertical movement of $100 \mu \mathrm{m}$ at 10 hertz was then immediately immersed in the sample, allowing to record the $\tan \delta$ value versus time. Additionally, the cement HBS-0 reference (with no DGL nor PEG-NHS) was also studied for comparison.

\subsubsection{High frequency impedance measurements}

The high frequency impedance measurements were recorded, between 0.4 and $100 \mathrm{MHz}$, with a HP 4194 A impedance/gain-phase analyser (Hewlett-Packard) at $37^{\circ} \mathrm{C}$, using an experimental setup reported previously. ${ }^{44}$

The experimental device was completed by a computer allowing automatic data acquisition and real-time calculation of the complex impedance, $Z^{*}$ from which the dielectric permittivity, $\varepsilon^{\prime}$ (related to dipole variation), and dielectric losses, $\varepsilon "$ (related to the motion of free charges), were computed. ${ }^{51}$

\subsubsection{Injectability and cohesion assessment}


An AMETEK LS5 texture analyzer was used to assess the injectability of the different samples 15 minutes after starting the paste preparation. This consisted in measuring the compression force necessary to extrude the cement paste samples from a syringe (inner diameter of the cartridge $8.2 \mathrm{~mm}$, inner diameter of the exit hole $1.7 \mathrm{~mm}$, extrusion rate $1 \mathrm{~mm} . \mathrm{s}^{-}$

${ }^{1}$ at $\left.15 \mathrm{~min}\right)$. At the end, the percentage of paste extruded was determined.

Cohesion assessment was conducted 5 and 15 min after starting the paste preparation. For that purpose, the paste was directly extruded into a $0.9 \mathrm{wt} \% \mathrm{NaCl}$ solution, and a visual check of the extruded filaments was done 24 hours after extrusion, showing either a shape retention or a disaggregation depending whether the paste was cohesive or not.

\subsubsection{Statistical analysis}

For DMA, each measure of $\tan \delta$ was repeated 3 times per condition. For the obtained experimental results, statistical analyses were performed with Statgraphics (Statgraphics Technologies, Virginia, USA). Data values are presented as mean \pm standard error (SE) and conditions were compared with a multiple-sample comparison test with a least significant difference post hoc analysis, for a 95\% confidence level $(\mathrm{p}<0.05)$.

For each condition, the high frequency impedance experiments were duplicated and the standard deviation on deduced initial and final setting times was estimated to be between 1 and $6 \%$, consistent with previous similar studies performed on other CPC systems. ${ }^{44}$

For the injectability assessment, analysis of variance (ANOVA) was performed on the applied extrusion force data for the HBS- 0 and CPC composites samples prepared using 2 or 5 wt.\% aqueous $\mathrm{Na}_{2} \mathrm{HPO}_{4}$, with $\alpha=0.05$ (meaning that, for $\mathrm{p}<0.05$, at least one group of samples was statistically different compared with the other groups). To identify the sample or samples that was/were significantly different, a statistical study for each applied extrusion force result was carried out using F-test followed by two-tailed $t$-test (two tail analysis).

For the compressive strength measurements, six cylinders were used for each sample to 
calculate the mean and standard deviation (SD). Analysis of variance (ANOVA) was performed on the compressive strength data for the HBS- 0 and CPC composites samples prepared using 2 or 5 wt. $\%$ aqueous $\mathrm{Na}_{2} \mathrm{HPO}_{4}$, with $\alpha=0.05$ (meaning that, for $\mathrm{p}<0.05$, at least one group of samples was statistically different compared with the other groups). To identify the sample or samples that was/were significantly different, a statistical study for each mechanical result was carried out using F-test followed by two-tailed $t$-test.

\section{Results}

To make sure that the hydrogel formation only starts once the cement paste is prepared, one of the two hydrogel precursors was combined to the solid phase of the CPC while the other was dissolved in the liquid phase. To minimize undesired hydrolysis of the N-hydrosuccinimide groups, the PEG-NHS compound was mixed with the cement powder.

\subsection{Behavior of the hydrogel precursors under the conditions of the CPC workup}

In a first step, the solubility of the PEG-NHS and DGL compounds in the CPC liquid phase (i.e. 5 wt. $\% \mathrm{Na}_{2} \mathrm{HPO}_{4}$ ) was investigated, showing that DGL is soluble in this medium (up to 40 $\mathrm{mg} \mathrm{mL} \mathrm{m}^{-1}$ ). On the other hand, the solubility limit of PEG-NHS was only $180 \mathrm{mg} \mathrm{mL}^{-1}$, but was found to be shifted to $910 \mathrm{mg} \mathrm{mL}^{-1}$ in a $2 \mathrm{wt} . \% \mathrm{Na}_{2} \mathrm{HPO}_{4}$ solution. Then the formation of the hydrogel was assessed in a 5 wt.\% $\mathrm{Na}_{2} \mathrm{HPO}_{4}$ solution, respectively below (DGL: $24 \mathrm{mg} \mathrm{mL}^{-1}$, PEG-NHS: $150 \mathrm{mg} \mathrm{mL}^{-1}$, noted 24/150) and above (40/250) the PEG-NHS solubility limit. After a 30 minutes cross-linking time, the resulting hydrogel were rinsed three times with water and dried. When operating below the PEG-NHS solubility limit (e.g. 24/150) the amount of recovered solid was ca. $90 \%$ of the initial mass of reagents, while it dropped to $66 \%$ when operating above the PEG-NHS solubility limit (e.g. 40/250), giving evidence that part of the PEG-NHS was unreacted in that case and then washed out of the hydrogel during the rinsing steps. 


\subsection{Monitoring of the setting time of the CPC composites by high frequency impedance measurements}

During the hardening process of apatitic CPCs, the major component of the solid phase (alphatricalcium phosphate, noted $\alpha$-TCP) slowly dissolves, leading to a saturation of the liquid phase in calcium and phosphate ions which results in the rapid precipitation of a less soluble and thermodynamically more stable calcium phosphate in the intergranular space, i.e. calciumdeficient hydroxyapatite (CDA). The entanglement of these apatite crystals makes the CPC harden. High frequency impedance was used to monitor this reaction ${ }^{44}$ and the recorded complex impedance data allowed to deduce the profile of:

(i) the dielectric permittivity $(\varepsilon$ ') that showed a rapid increase due to the accumulation of mobile unbound charged species on the surface of the solid reactants leading to a supersaturated solution, followed by a maximum corresponding to a full coverage of the $\alpha$-TCP surface by a semi-permeable CDA shell; then an aging period takes place, characterized by a constrained diffusion of water and ions towards the inner part of the $\alpha$-TCP particles and the formation of a less conductive final setting product;

(ii) dielectric losses $(\varepsilon ")$ which are related to the motion of free charges that decrease as the precipitation of apatite starts leading to a progressive hardening of the cement paste.

In a final step, when the diffusion of reactive species through the CDA layer gets too limited, dielectric parameters reach a constant value. Therefore, the evolution of the $\varepsilon$ ' and $\varepsilon$ " experimental values during the setting reaction was recorded for the different composites, by comparison with the corresponding polymer-free references (Table 1 - Figure 2 and Figure S1 in Supporting information). 
Under standard conditions (no hydrogel precursor - 5 wt.\% $\mathrm{Na}_{2} \mathrm{HPO}_{4}$ ), the hydrolysis of $\alpha-$ TCP, promoted by $\mathrm{Na}_{2} \mathrm{HPO}_{4}$, started rapidly after mixing the liquid and solid components resulting in a precipitation of CDA in the intergranular space over a ca. 40 minutes period. This was evidenced by the variation of the dielectric parameters which was quite smooth during the first 20 minutes, before getting sharper ( $\varepsilon^{\prime}$ (large $\uparrow$ ) and $\varepsilon^{\prime \prime}$ (rapid $\left.\downarrow\right)$ ). When the hydrogel precursors were added in the cement composition, the same trend was observed although the CDA precipitation in the intergranular space extended for a longer period in direct proportion with the amount of hydrogel precursors loaded in the cement composition (i.e. ca. 40 minutes for 16/100; ca. 70 minutes for 24/150 - Figure S1 in Supporting information).

By contrast, when the phosphate concentration in the liquid phase was lower (i.e. 2 wt.\% $\mathrm{Na}_{2} \mathrm{HPO}_{4}$ ), the precipitation of apatite in the intergranular space was significantly delayed in the absence of any additive, as shown by the $\varepsilon$ ' value which remained almost constant for one hour before the CDA precipitation started (0/0 - Figure 2). Interestingly, when increasing amounts of hydrogel precursors were combined to the CPC, the initiation of the setting reaction was more and more shifted towards longer times (from $160 \mathrm{~min}$ for 16/100 to $375 \mathrm{~min}$ for 40/250) and the CDA precipitation occurred over a longer period (ca. 170 minutes versus 40 minutes for the undoped HBS-0 reference).

\subsection{Dynamic mechanical analyses (DMA)}

DMA was used to monitor changes in the energy dissipation of the CPC references, hydrogels and CPC composites, under cyclic loading as a function of time.

In a first experiment, a solution of DGL in aqueous $\mathrm{Na}_{2} \mathrm{HPO}_{4}(2$ or $5 \mathrm{wt} . \%)$ was mixed for 1 minute with the solid form of PEG-NHS, and the resulting mixtures were analyzed. The concentration of the two hydrogel precursors with respect to the liquid phase were the same as those investigated for the CPC composites (i.e. DGL/PEG-NHS $=8 / 50,16 / 100,24 / 150$ or 
40/250 $\mathrm{mg} \mathrm{mL}^{-1}$ ). As expected, a variation of the tangent of the phase angle was observed when the mixtures evolved from a liquid state to an elastomer state, once the reticulation of the hydrogel has occurred (Figure 3 and Figure S2).

The time elapsed at the beginning (ca. 60 seconds) and at the end (300-900 seconds) of this variation are reported in Table 2, giving an indication on the time range for the formation of the hydrogel network, in the absence of the CPC powder.

The usual way to assess the initial and final setting time of CPC is the use of the Gillmore needles standard test method, by measuring the change in the material's penetration resistance. However, in the present case, the reticulation of the organic polymer most often conferred an elastic character to the cement paste, which made indentation hardly observable. Hence, the Gillmore needles method was not appropriate for the present study. For this reason, DMA experiments were used to monitor the setting of the CPC composites by comparison with the HBS-0 references. For the two references, the CPC powder was mixed with the aqueous disodium phosphate solution ( 2 or $5 \mathrm{wt} . \%$ ) for 1 minute, and the resulting paste was then analyzed by DMA. For the composites, the same procedure was carried out, i.e. the DGL solution was added to the HBS-0 powder combined with PEG-NHS, and after mixing (1 minute), the resulting cement paste was analyzed (Figures S3 and S4). Figure 4 shows typical DMA curves, obtained for the HBS-0 cement reference and the 24/150 composite both prepared using a 5 wt. $\%$ aqueous $\mathrm{Na}_{2} \mathrm{HPO}_{4}$ solution. A progressive increase of $\tan \delta$ was observed during the first 20 minutes for the CPC reference, giving evidence of a gradual thickening of the cement paste as the cement setting reaction takes place (i.e. precipitation of apatite crystals in the intergranular space). A maximum was then reached and the signal became erratic until a sharp return to the baseline, as a consequence of the cement rigidification. When the hydrogel precursors were added to the cement, similar profiles were observed. However, a low decrease of $\tan \delta$ was observed during the first 12 minutes, possibly due to a higher fluidity of the cement 
paste caused by the presence of the hydrogel precursors. Then a linear increase was observed, linked to the concomitant reticulation of the hydrogel and cement setting reaction, followed by a longer erratic plateau before returning to baseline. The time elapsed for these three particular events are reported in Table 3.

By contrast, when the phosphate concentration in the liquid phase was lower (i.e. 2 wt.\% $\mathrm{Na}_{2} \mathrm{HPO}_{4}$ ), the variation of $\tan \delta$ started significantly later for the HBS-0 reference since the setting reaction was delayed in these conditions (Figure S3). Interestingly, the variation of tan $\delta$ started earlier in the case of the CPC composites, as a result of the rapid hydrogel formation that occurred faster than the precipitation of apatite in the intergranular space.

From a clinical perspective, it was important to determine how long molding/shaping is possible and when surgical closure of the wound might be initiated when using this type of CPC composite. Interestingly, while the Gillmore needles method was not appropriate for this purpose, this information can be assessed from the DMA measurements. Indeed, the time elapsed at the end of the increase of the $\tan \delta$ can be considered as the limit value that should not be exceeded for manipulating the CPC composites. On the other hand, the time elapsed for the $\tan \delta$ to return to the baseline corresponds to the complete rigidification of the material. In the case of the 8/50,16/100 and 24/150 CPC composites prepared in 2 wt. $\% \mathrm{Na}_{2} \mathrm{HPO}_{4}$, these two characteristic values (15-20 and 38-47 minutes, respectively) were found to be in the same range than for the HBS reference ( 5 wt.\% $\mathrm{Na}_{2} \mathrm{HPO}_{4}$ ) which is currently used in clinics (17 and 31 minutes, respectively).

\subsection{Characterization of the microstructural and mechanical properties of the CPC composites}

In order to investigate whether a 3D organic hydrogel network has formed in the different CPC composites, molden cylindrical cement blocks (setting time: 1 week) were immerged in a 10 
wt.\% solution of ethylenediaminetetraacetic acid (EDTA) for 2 weeks. The reaction with EDTA specifically resulted in the full dissolution of the calcium phosphate component. When present, the organic component remaining after the decalcification process was submitted to successive washings to finish with a supercritical drying step using carbon dioxide, to allow observation of the samples by scanning electron microscopy. Results about the decalcification experiments are summarized in Table 4 for the different conditions, i.e presence or absence of an organic residue, shape and behavior of the residue (see Figure S5).

One important feature for the practical use of calcium phosphate cements, is their ability to reach an appropriate cohesion after a few minutes, to ensure that no disaggregation of the cement paste will occur on the implantation site where bleeding often takes place. Hence, the cohesion of the different composites was studied by extrusion of the paste into a $0.9 \mathrm{wt} \% \mathrm{NaCl}$ solution at $37^{\circ} \mathrm{C}, 15$ minutes after the preparation of the cement paste (see Figure S6). By contrast with the HBS-0 reference that was not cohesive in any of the tested conditions (i.e. using a 2 or 5 wt. $\%$ aqueous $\mathrm{Na}_{2} \mathrm{HPO}_{4}$ solution as the CPC liquid phase), a correct to very good cohesion was observed for all the composites. In addition, while the 40/250 sample (2 wt.\% aqueous $\mathrm{Na}_{2} \mathrm{HPO}_{4}$ ) was found to be very cohesive, a swelling of the cement paste was observed as well.

The injectability of the cement pastes and their behavior under pressure was assessed using extrusion tests. ${ }^{13,15,52}$ After mixing the solid and liquid phases for one minute, the different samples were put in a syringe and extruded at a constant rate 15 minutes after the paste preparation. Typically, the extrusion force rapidly reaches a plateau, followed by a very sharp increase which corresponds either to the beginning of the hardening process, or a filter-pressing phenomenon (i.e. phase segregation between the liquid and solid phases) or a full injection of the paste. As shown in Table 4, only two conditions [40/250, 2 wt.\% aqueous $\mathrm{Na}_{2} \mathrm{HPO}_{4}-$ 16/100, 5 wt.\% aqueous $\mathrm{Na}_{2} \mathrm{HPO}_{4}$ ) were found for which the full content of the syringe could 
be injected (> 90\%). In both cases the force to apply was very low when compared to the commercial HBS® reference and statistically different ( $\mathrm{p}$ values were 0 in $t$-test). Surprisingly, the compressive strengths $(\mathrm{MPa})$ were in the similar range for all the series of composites.

SEM observations of polished cross-sections of the CPC composites were performed to compare their microstructure. When using a 5 wt.\% aqueous $\mathrm{Na}_{2} \mathrm{HPO}_{4}$ solution as the liquid phase, different types of particles can be observed for the polymer-free HBS-0 reference, the size of which is representative of the granulometry of the CPC powder (size distribution: 1.4$32 \mu \mathrm{m}$ average size $=9 \mu \mathrm{m}-$ Figure 5): (i) a small amount of those are dense, either along their whole cross-section or in their inner part, and correspond to unreacted or partially hydrolyzed $\alpha$-TCP or DCPD; (ii) a large amount of particles have a geode-like morphology with a dense shell lined in its inner part with interdigitated platelet crystals, as a result of a full hydrolysis of $\alpha$-TCP into CDA (Figure 6).

The area in between all these particles is mostly occupied by CDA platelet crystals forming channels with a "sand rose" architecture, having a typical width of ca. 1-3 microns. No significant change in the microstructure was observed when increasing amounts of DGL and PEH-NHS (8/50, 16/100 and 24/150 CPC composites) were introduced in the formulation (see Figure 6). When using a 2 wt.\% aqueous $\mathrm{Na}_{2} \mathrm{HPO}_{4}$ solution as the liquid phase, a similar microstructure was also present for the polymer-free HBS-0 reference (Figure 7). However, addition of DGL and PEH-NHS led to a significant modification of the microstructure, in particular for the 24/150 and 40/250 CPC composites (Figure 8): firstly, a decrease of the size of the transformed $\alpha$-TCP particles has occurred and their morphology has changed as well. Hence, it becomes more difficult to differentiate them from the network of platelet crystals present in the intergranular space, the size of which is significantly larger at some places, when compared to the CPC reference. 
In order to characterize the organic component present in the CPC composites, SEM observations of a fracture plane of the decalcified samples were also performed. Images of the decalcified 24/150 and 40/250 CPC composites (liquid phase : 2 wt.\% aqueous $\mathrm{Na}_{2} \mathrm{HPO}_{4}$ solution) are presented in Figure 9, showing that the continuous 3D organic network present in the two materials is highly porous and corresponds to the negative imprint of apatite crystals formed during the setting process. The main difference between the two samples lies in the fact that the polymer scaffold formed in the 40/250 CPC composite was rigid enough to retain its shape after dissolution of the calcium phosphate component and supercritical drying. By contrast, an important shrinkage was observed for the 24/150 sample during the drying process.

\section{Discussion}

The main objective of this study was to investigate in which extent the general properties of an injectable apatitic cement might be affected when introducing in the cement formulation synthetic precursors that would self-assemble to form a biocompatible hydrogel once the CPC solid and liquid phases are mixed. Indeed, the formation of a 3D continuous organic network in the intergranular space might alter the precipitation and crystal growth of apatite which is the driving force of the cement setting reaction.

For that purpose, two reagents capable to form a biocompatible hydrogel in a few minutes were introduced into a polymer-free CPC formulation (HBS-0): a $10 \mathrm{kDa}$ polyethyleneglycol chain end-capped with two N-hydrosuccinimide groups (noted PEG-NHS) that was mixed to the solid phase of the CPC, and a third generation cross-linked dendrimer grafted with lysine end-groups (noted DGL) $^{50}$ which was dissolved in the liquid phase. While the relative DGL / PEG-NHS weight ratio was kept constant $(0.16)$, the total amount of the two precursors introduced in the CPC formulation was allowed to vary. A limited solubility of the PEG-NHS component was noted when using the normal liquid phase for Graftys $\mathrm{HBS} \circledast$ (i.e. 5 wt.\% aqueous $\mathrm{Na}_{2} \mathrm{HPO}_{4}$ ) 
and for this reason, a less concentrated solution ( 2 wt.\% aqueous $\mathrm{Na}_{2} \mathrm{HPO}_{4}$ ) was also investigated in this work, to allow a higher loading of the hydrogel precursors.

For the two liquid phases, conditions similar to the preparation of the cement paste were used to assess the kinetics of the formation of the hydrogel in the absence of the CPC powder. On the basis of dynamic mechanical analyses, the transition from the liquid to hydrogel state started after ca. 1 minute and ended after about 4-14 minutes, depending on the liquid phase and amount of hydrogel precursors. On the other hand, high frequency impedance measurements showed that in the case of the $5 \mathrm{wt} . \%$ aqueous $\mathrm{Na}_{2} \mathrm{HPO}_{4}$ solution, the precipitation of apatite crystals was found to occur in the same time range than the hydrogel formation. By comparison with the polymer-free HBS-0 reference, the end of the inorganic network formation was shifted towards longer times in direct proportion with the amount of hydrogel precursors loaded in the cement composition (i.e. ca. 40 minutes for 0/0, 70 minutes for 16/100, and 100 minutes for 24/150 - Figure S1 in Supporting information). The same trend was observed using DMA, since the higher the content in hydrogel precursors, the longer the time before rigidification of the cement paste (i.e. ca. 30 minutes for 0/0, 33 minutes for 8/50, 65 minutes for 16/100, and 71 minutes for $24 / 150$ - see Table 3 ). Finally no significant change in the microstructure was observed upon addition of PEG-NHS and DGL in the CPC formulation (Figures 5 and 6). These results all together suggest that the concomitant formation of the organic and inorganic networks affects both reactions since (i) either no hydrogel (8/50) or a poorly reticulated organic network was formed (16/100 and 24/150), as evidenced by the decalcification experiments; (ii) the kinetic of the setting reaction driven by the precipitation of apatite crystals in the intergranular structure was slowed down, as the amount of hydrogel precursors was increased. Moreover, for the 3 composites, the compressive strengths (MPa) were in the same range. While the cohesion and injectability of the HBS-0 reference were insufficient (see Table 4), the 3 composites showed however a very good cohesion 15 minutes after preparation of the cement 
paste, and the injectability was also found to be correct, except for the 24/150 composite for which the force needed for extrusion was very high (ca. $40 \mathrm{~N}$ ). All CPC composite samples exhibited a statistically significant difference from HBS-0 reference and between them ( $p$ values were $\sim 0$ in $t$-test). In summary, while the commercial Graftys HBS $®$ cement contains 2 wt.\% hydroxypropyl methyl cellulose (HPMC) to provide suitable cohesion and injectability, similar performances were obtained with DGL/PEG-NHS for the 8/50 and 16/100 composites.

By contrast, the use of a 2 wt.\% aqueous $\mathrm{Na}_{2} \mathrm{HPO}_{4}$ solution resulted in a slower sursaturation of the liquid phase with calcium and phosphate ions, so that the cement setting reaction was delayed by one hour for the HBS-0 reference (see Figure 2). Therefore, the formation of the hydrogel took place prior to the apatite precipitation, and the presence of a 3D organic network was evidenced for the 4 composites thanks to the decalcification experiments (Table 4). In the case of the $24 / 150$ and $40 / 250$ composites, the density of the hydrogel was found to be high enough to allow the material to self-support in water once the inorganic network has been removed. Interestingly, after decalcification of the 40/250 composite, the size of the hydrogel was even found to have expanded by ca. $15 \%$ in water with respect with the initial size of the hardened cement block and these dimensions were also preserved after drying, by contrast with the other composites for which a shrinkage of ca. $55 \%$ was observed when dried using supercritical carbon dioxide.

Due to the rapid formation of the hydrogel in the intergranular space, the setting reaction was therefore hampered, as confirmed by the high frequency impedance and DMA measurements showing that the formation of the inorganic network was even more delayed when increasing the amounts of DGL and PEG-NHS introduced in the CPC formulation. In terms of cohesion, all the composites were cohesive. As regards the injectability, filter-pressing was present for the $8 / 50$ and $16 / 100$ composites, while the injectability was found to be excellent for the 40/250 sample, for which the totality of the paste could be extruded and the force to apply was very 
low, giving evidence of the high fluidity of this material. All the CPC composites exhibited a statistically significant difference from the HBS-0 reference and between them ( $\mathrm{p}$ values were $\sim 0$ in $t$-test).

Once hardened, in particular for the 24/150 and 40/250 CPC composites, the observed microstructure significantly differed from that of the HBS-0 reference (Figures 7 and 8). Firstly, the size of the transformed $\alpha$-TCP particles was smaller. Normally, the hydrolysis of the $\alpha$ TCP particles results in (i) the concomitant precipitation of apatite needles on their surface with the formation of a dense shell (see Figure 8(a)) and their size once transformed does not change much; (ii) the precipitation of CDA platelet crystals with a "sand rose" architecture in the intergranular space. By contrast, in the case of the 24/150 and 40/250 CPC composites, likely because the $\alpha$-TCP particles were embedded in the 3D organic network before the setting reaction started, the dissolution of $\alpha$-tricalcium phosphate mainly results in the precipitation of platelet crystals within the porous polymer scaffold (Figure 8(d)). Moreover, the size of the apatite crystals was significantly larger at some places, when compared to the CPC reference, as a result of a probable confinement effect that leads to a slower crystal growth. Finally, no significant improvement was again observed in terms of compressive strength (MPa) upon addition of PEG-NHS and DGL in the CPC formulation. However, while the fracture of the polymer-free HBS-0 reference led to the formation of a large amount of small debris due to its brittle character, compression of the CPC composites led to a deformation and crushing of the samples as a result of the embedment of the apatite crystals in the organic network, with a generation of a very limited amount of small debris.

\section{Conclusion}

The introduction of polymers in calcium phosphate cements is a common strategy to make them injectable and improve their cohesion, but at the end the polymer is simply trapped in the CPC 
structure and no organic sub-network is present. In the present study, organic monomers were combined to a CPC and conditions were found to make them reticulate in situ to form a biocompatible 3D polymeric scaffold in the intergranular space, before the growth of the apatitic inorganic network had started. Hence, the precipitation of apatite occurred within the porous polymer network, and the organic component was shown to strongly affect the size, density and arrangement of the apatite crystals formed during the setting reaction, thereby leading to an original microstructure. From a clinical perspective, some of the composites reported here were found to be similar to clinically used CPCs, in terms of cohesion and setting time, with an even better injectability. Moreover, given that the polymer formed in the CPC was previously shown to be non-cytotoxic and to act as a support promoting cellular attachment and proliferation, while being biocompatible and degraded in vivo through phagocytosis by macrophages, it might offer great potential in the context of bone regeneration and repair. Finally, the presence of this hydrophilic polymeric sub-network in the composites might confer a higher permeability to the CPC. It would thus be of great interest to investigate whether this change in the microstructure might result in a different in vivo behavior, in terms of resorption rate when implanted in bone defects.

Another potential interest is the opportunity offered by the aqueous environment used to crosslink the DGL and PEG-NHS to entrap water-soluble compounds in the hydrogel. For instance, the incorporation of a recombinant elastin derived protein was shown to enhance the elastic modulus of the resulting hydrogels ${ }^{48}$ and this might be an attractive strategy to further improve the mechanical properties of these CPC composites.

\section{Disclosure}

Some authors of this publication have research support from Graftys SA. The terms of this arrangement have been reviewed and approved by both CNRS and the University of Nantes in 
accordance with their policy on objectivity in research.

\section{Acknowledgements}

This work was partially supported by BPI-France $\left(23^{\text {rd }}\right.$ call for R\&D proposals of FUI - grant DOS0056563/00 - SpineFlex project), and the COLCOM and Graftys companies. The authors greatly acknowledge the Scanning Electron Microscopy facility at the Institut des Matériaux Jean Rouxel (IMN) laboratory, and particularly Nicolas Stephant for his technical support. The authors greatly acknowledge Nathalie Guichard from the CEISAM laboratory for his help for the data acquisition related to injectability, cohesion and mechanical properties.

\section{References}

1. Brown WE, Chow LC. A new calcium phosphate setting cement. J Dent Res 1983;62:672-679.

2. LeGeros R, Chohayeb A, Shulman A. Apatitic calcium phosphates: possible restorative materials. J Dent Res 1982;61 (Special Issue):343.

3. Mirtchi AA, Lemaitre J, Terao N. Calcium-phosphate cements - study of the betatricalcium phosphate - monocalcium phosphate system. Biomaterials 1989;10:475-480.

4. Bajammal SS, Zlowodzki M, Lelwica A, et al. The use of calcium phosphate bone cement in fracture treatment. J Bone Joint Surg Am 2008;90A:1186-1196.

5. Carey LE, Xu HHK, Simon CG, Takagi S, Chow LC. Premixed rapid-setting calcium phosphate composites for bone repair. Biomaterials 2005;26:5002-5014.

6. Larsson S, Bauer TW. Use of injectable calcium phosphate cement for fracture fixation: A review. Clin Orthop Relat Res 2002:23-32.

7. Larsson S, Hannink G. Injectable bone-graft substitutes: Current products, their characteristics and indications, and new developments. Injury 2011;42:S30-S34.

8. Bohner M, Gbureck U, Barralet JE. Technological issues for the development of more efficient calcium phosphate bone cements: A critical assessment. Biomaterials 2005;26:64236429.

9. Dorozhkin SV. Calcium orthophosphate cements for biomedical application. J Mater Sci 2008;43:3028-3057.

10. Dorozhkin SV. Self-setting calcium orthophosphate formulations. J Funct Biomater 2013;4:209-311.

11. Ginebra MP, Espanol M, Montufar EB, Perez RA, Mestres G. New processing approaches in calcium phosphate cements and their applications in regenerative medicine. Acta Biomater 2010;6:2863-2873.

12. Khairoun I, Magne D, Gauthier O, et al. In vitro characterization and in vivo properties of a carbonated apatite bone cement. J Biomed Mater Res 2002;60:633-642. 
13. Bohner M, Baroud G. Injectability of calcium phosphate pastes. Biomaterials 2005;26:1553.

14. Habib M, Baroud G, Gitzhofer F, Bohner M. Mechanisms underlying the limited injectability of hydraulic calcium phosphate paste. Acta Biomater 2008;4:1465-1471.

15. Khairoun I, Boltong MG, Driessens FCM, Planell JA. Some factors controlling the injectability of calcium phosphate bone cements. J Mater Sci Mater Med 1998;9:425-428.

16. O'Neill R, McCarthy HO, Montufar EB, et al. Critical review: Injectability of calcium phosphate pastes and cements. Acta Biomater 2017;50:1-19.

17. Bohner M, Doebelin N, Baroud G. Theoretical and experimental approach to test the cohesion of calcium phosphate pastes. Eur Cells Mater 2006;12:26-35.

18. Chen G, Li W, Yu X, Sun K. Study of the cohesion of TTCP/DCPA phosphate cement through evolution of cohesion time and remaining percentage. J Mater Sci 2009;44:828-834.

19. Fernandez E, Gil FJ, Best SM, Ginebra MP, Driessens FCM, Planell JA. Improvement of the mechanical properties of new calcium phosphate bone cements in the CaHPO4-alphaCa-3(PO4)(2) system: Compressive strength and microstructural development. J Biomed Mater Res 1998;41:560-567.

20. Johnson AJW, Herschler BA. A review of the mechanical behavior of $\mathrm{CaP}$ and $\mathrm{CaP} /$ polymer composites for applications in bone replacement and repair. Acta Biomater 2011;7:16-30.

21. Zhang J, Liu W, Schnitzler V, Tancret F, Bouler J-M. Calcium phosphate cements for bone substitution: Chemistry, handling and mechanical properties. Acta Biomater 2014;10:1035-1049.

22. Zhang JT, Tancret F, Bouler JM. Fabrication and mechanical properties of calcium phosphate cements (CPC) for bone substitution. Mater Sci Eng C Mater Biol Appl 2011;31:740747.

23. del Real RP, Ooms E, Wolke JGC, Vallet-Regi M, Jansen JA. In vivo bone response to porous calcium phosphate cement. J Biomed Mater Res Part A 2003;65A:30-36.

24. Gauthier O, Bouler JM, Aguado E, Pilet P, Daculsi G. Macroporous biphasic calcium phosphate ceramics: influence of macropore diameter and macroporosity percentage on bone ingrowth. Biomaterials 1998;19:133-139.

25. Xu HHK, Takagi S, Quinn JB, Chow LC. Fast-setting calcium phosphate scaffolds with tailored macropore formation rates for bone regeneration. J Biomed Mater Res Part A 2004;68A:725-734.

26. Alkhraisat MH, Rueda C, Marino FT, et al. The effect of hyaluronic acid on brushite cement cohesion. Acta Biomater 2009;5:3150-3156.

27. Ishikawa K, Miyamoto Y, Kon M, Nagayama M, Asaoka K. Non-decay type fast-setting calcium-phosphate cement - composite with sodium alginate. Biomaterials 1995;16:527-532.

28. Lin JP, Zhang SN, Chen T, Liu CS, Lin SL, Tian XH. Calcium phosphate cement reinforced by polypeptide copolymers. J Biomed Mater Res Part B 2006;76B:432-439.

29. Liu H, Li H, Cheng WJ, Yang Y, Zhu MY, Zhou CR. Novel injectable calcium phosphate/chitosan composites for bone substitute materials. Acta Biomater 2006;2:557-565.

30. Liu W, Zhang J, Rethore G, et al. A novel injectable, cohesive and toughened Si-HPMC (silanized-hydroxypropyl methylcellulose) composite calcium phosphate cement for bone substitution. Acta Biomater 2014;10:3335-3345.

31. Liu W, Zhang J, Weiss P, Tancret F, Bouler J-M. The influence of different cellulose ethers on both the handling and mechanical properties of calcium phosphate cements for bone substitution. Acta Biomater 2013;9:5740-5750.

32. Miyamoto Y, Ishikawa K, Takechi M, et al. Basic properties of calcium phosphate cement containing atelocollagen in its liquid or powder phases. Biomaterials 1998;19:707-715.

33. Tajima S, Nishimoto N, Kishi Y, Matsuya S, Ishikawa K. Effects of added sodium 
alginate on mechanical strength of apatite cement. Dent Mater J 2004;23:329-334.

34. Takagi S, Chow LC, Hirayama S, Eichmiller FC. Properties of elastomeric calcium phosphate cement-chitosan composites. Dent Mater 2003;19:797-804.

35. $\mathrm{Xu}$ HHK, Simon CG. Fast setting calcium phosphate-chitosan scaffold: mechanical properties and biocompatibility. Biomaterials 2005;26:1337-1348.

36. Zhang J, Liu W, Gauthier O, et al. A simple and effective approach to prepare injectable macroporous calcium phosphate cement for bone repair: Syringe-foaming using a viscous hydrophilic polymeric solution. Acta Biomater 2016;31:326-338.

37. Burguera EF, Xu HHK, Weir MD. Injectable and rapid-setting calcium phosphate bone cement with dicalcium phosphate dihydrate. J Biomed Mater Res Part B 2006;77B:126-134.

38. Cherng A, Takagi S, Chow LC. Effects of hydroxypropyl methylcellulose and other gelling agents on the handling properties of calcium phosphate cement. J Biomed Mater Res 1997;35:273-277.

39. Jyoti MA, Thai VV, Min YK, Lee B-T, Song H-Y. In vitro bioactivity and biocompatibility of calcium phosphate cements using Hydroxy-propyl-methyl-Cellulose (HPMC). Appl Surf Sci 2010;257:1533-1539.

40. Khairoun I, Driessens FCM, Boltong MG, Planell JA, Wenz R. Addition of cohesion promoters to calcium phosphate cements. Biomaterials 1999;20:393-398.

41. Song H-Y, Rahman AHME, Lee B-T. Fabrication of calcium phosphate-calcium sulfate injectable bone substitute using chitosan and citric acid. J Mater Sci Mater Med 2009;20:935941.

42. Thai VV, Lee B-T. Fabrication of calcium phosphate-calcium sulfate injectable bone substitute using hydroxy-propyl-methyl-cellulose and citric acid. J Mater Sci Mater Med 2010;21:1867-1874.

43. Wang X, Chen L, Xiang H, Ye J. Influence of anti-washout agents on the rheological properties and injectability of a calcium phosphate cement. J Biomed Mater Res Part B 2007;81B:410-418.

44. Despas C, Schnitzler V, Janvier P, et al. High-frequency impedance measurement as a relevant tool for monitoring the apatitic cement setting reaction. Acta Biomater 2014;10:940950.

45. Drury JL, Mooney DJ. Hydrogels for tissue engineering: scaffold design variables and applications. Biomaterials 2003;24:4337-4351.

46. Francoia J-P, Vial L. Everything You Always Wanted to Know about Poly-L-lysine Dendrigrafts (But Were Afraid to Ask). Chemistry-a European Journal 2018;24:2806-2814.

47. Romestand B, Rolland J-L, Commeyras A, et al. Dendrigraft Poly-L-lysine: A NonImmunogenic Synthetic Carrier for Antibody Production. Biomacromolecules 2010;11:11691173.

48. Debret R, Faye C, Sohier J, Sommer P. Polypeptide derived from tropoelastin and biocompatible material comprising same. Patent 2017;WO2017194761.

49. Lorion C, Faye C, Maret B, et al. Biosynthetic support based on dendritic poly(L-lysine) improves human skin fibroblasts attachment. Journal of Biomaterials Science-Polymer Edition 2014;25:136-149.

50. Collet H, Souaid E, Cottet H, et al. An Expeditious Multigram-Scale Synthesis of Lysine Dendrigraft (DGL) Polymers by Aqueous N-Carboxyanhydride Polycondensation. Chemistrya European Journal 2010;16:2309-2316.

51. Thiebaut JM, Roussy G, Chlihi K, Bessiere J. Dielectric study of the activation of blende with cupric ions. Journal of Electroanalytical Chemistry 1989;262:131-144.

52. Ginebra MP, Rilliard A, Fernandez E, Elvira C, San Roman J, Planell JA. Mechanical and rheological improvement of a calcium phosphate cement by the addition of a polymeric drug. J Biomed Mater Res 2001;57:113-118. 
Figure 1: Schematic structure of DGL; schematic representation of the reticulation process resulting from the reaction of PEG-NHS and DGL.

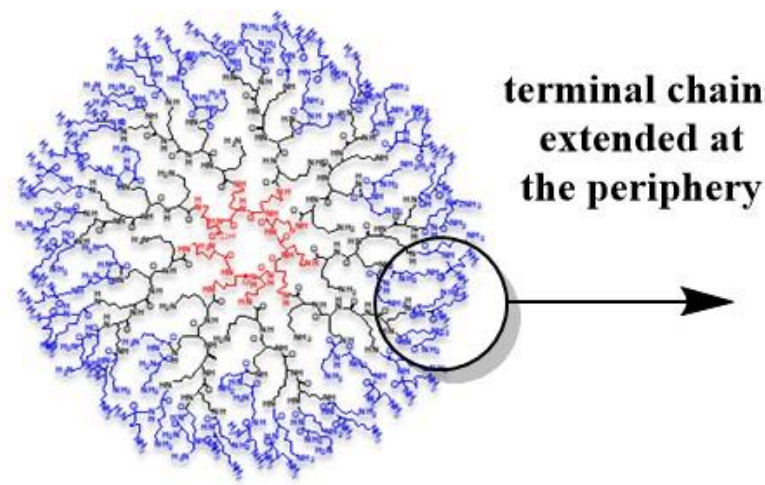

$$
\text { extended at }
$$

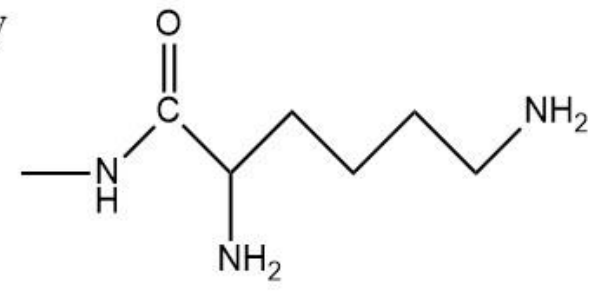

DGL<smiles>CCCC(=O)ON1C(=O)CCC1=O</smiles>

pH 8-9

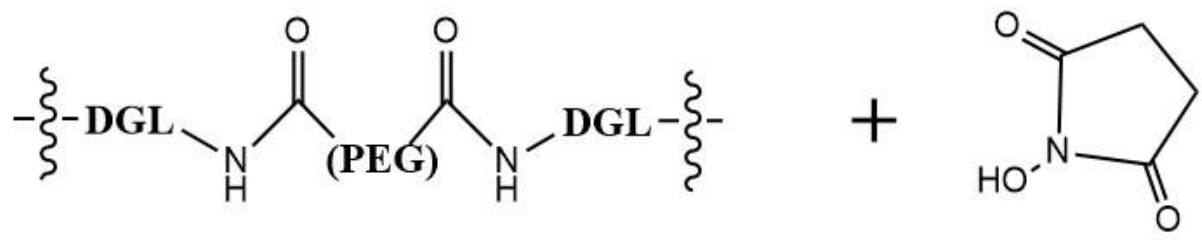


Figure 2. Variation of dielectric permittivity, $\varepsilon^{\prime}($ left), and dielectric losses, $\varepsilon "$ (right) versus reaction time for the HBS-0 reference (0/0) and the CPC composites loaded with DGL/PEGNHS: respectively, $16 \mathrm{mg} \mathrm{mL}^{-1} / 100 \mathrm{mg} \mathrm{mL}^{-1}, 24 \mathrm{mg} \mathrm{mL}^{-1} / 150 \mathrm{mg} \mathrm{mL}^{-1}$ and $40 \mathrm{mg} \mathrm{mL}^{-1} / 250$ mg mL ${ }^{-1}$, with a 2 wt. $\% \mathrm{Na}_{2} \mathrm{HPO}_{4}$ liquid phase. Frequency: $10 \mathrm{MHz}, 37^{\circ} \mathrm{C}$.
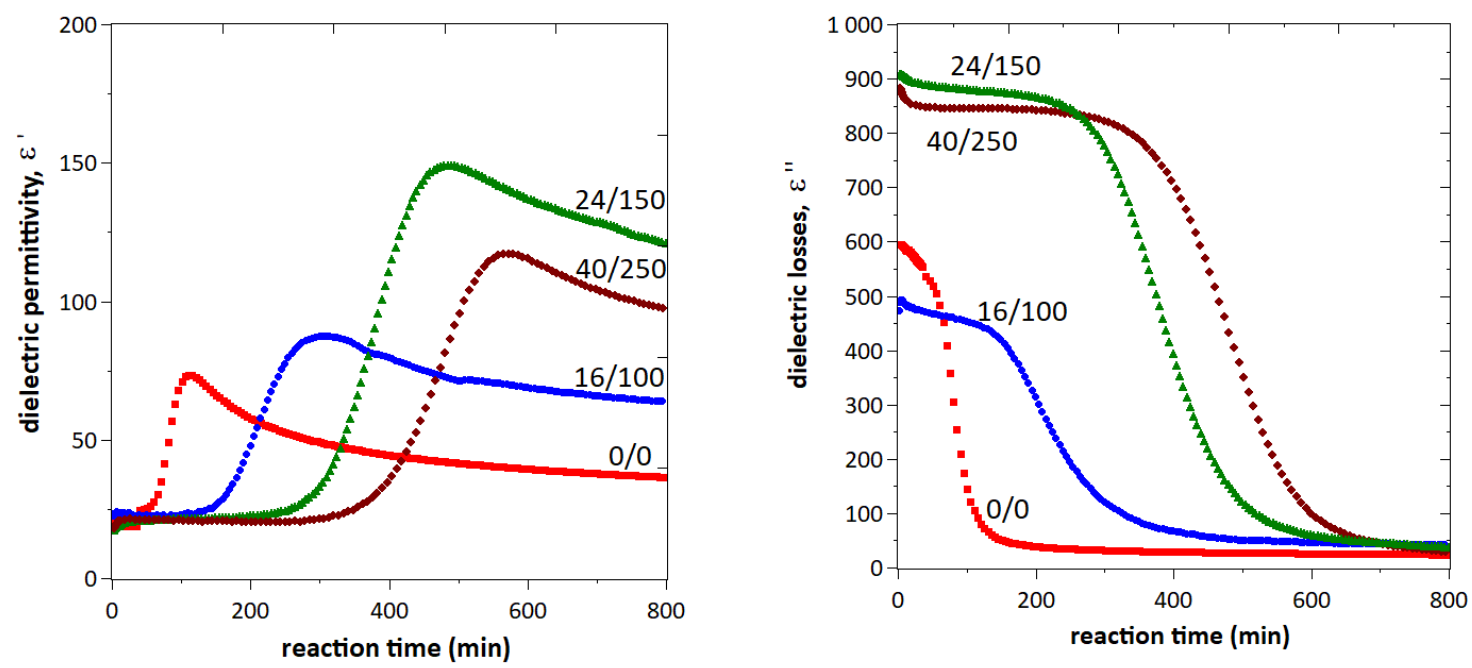
Figure 3. Variation of $\tan \delta$ versus time measured by DMA on a DGL solution $\left(16 \mathrm{mg} \mathrm{mL}^{-1}\right)$ in 2 wt.\% aqueous $\mathrm{Na}_{2} \mathrm{HPO}_{4}$ mixed with PEG-NHS $\left(100 \mathrm{mg} \mathrm{mL}^{-1}\right)$. The curves correspond to the repetition of three different experiments.

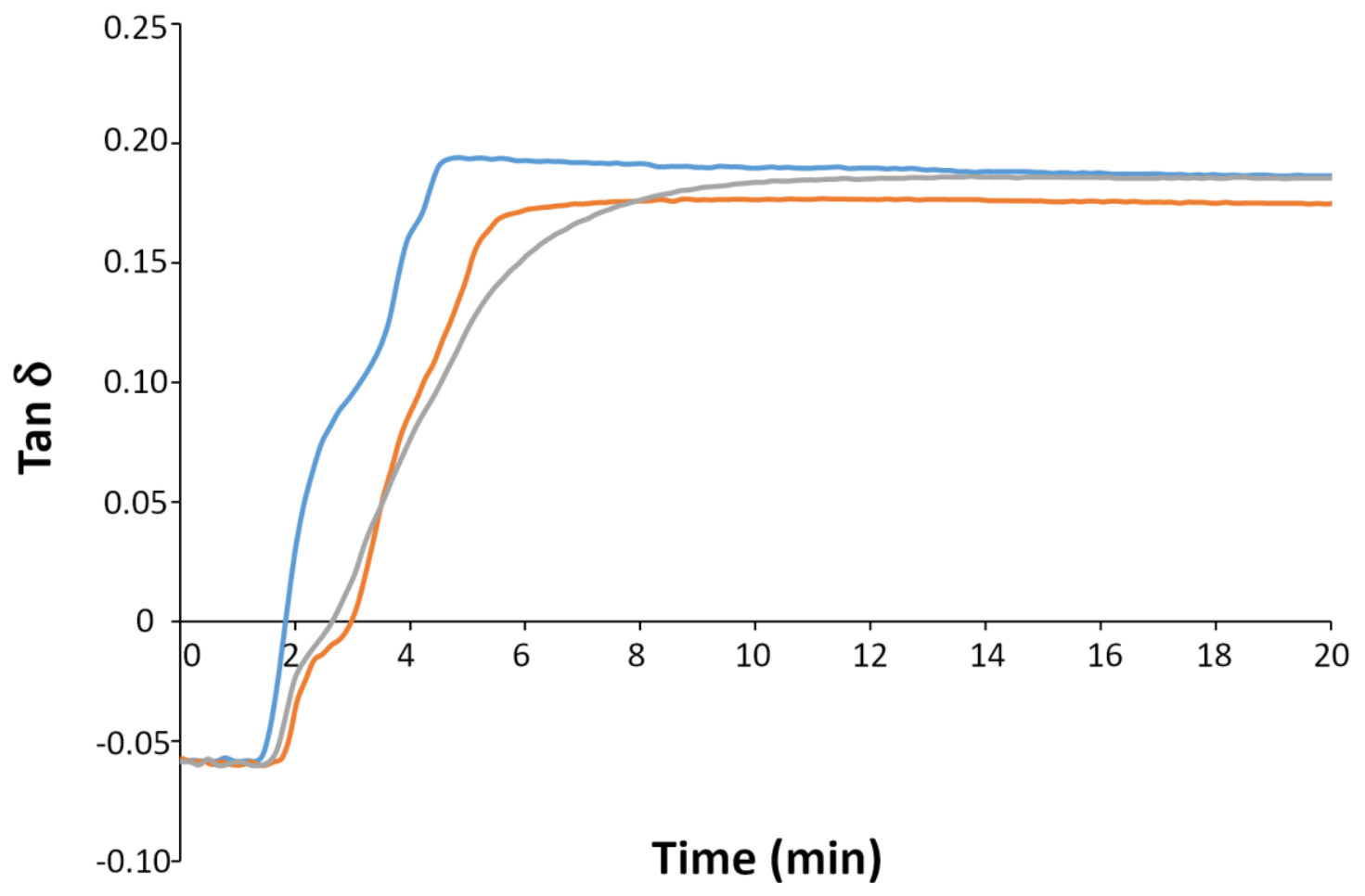


Figure 4. Variation of $\tan \delta$ versus time measured by DMA on a HBS-0 reference (red line) and a 24/150 CPC composite (black line), using a 5 wt.\% Na2HPO4 liquid phase. The arrow indicates the time at which the sample was introduced in the DMA apparatus and the measurement was started.

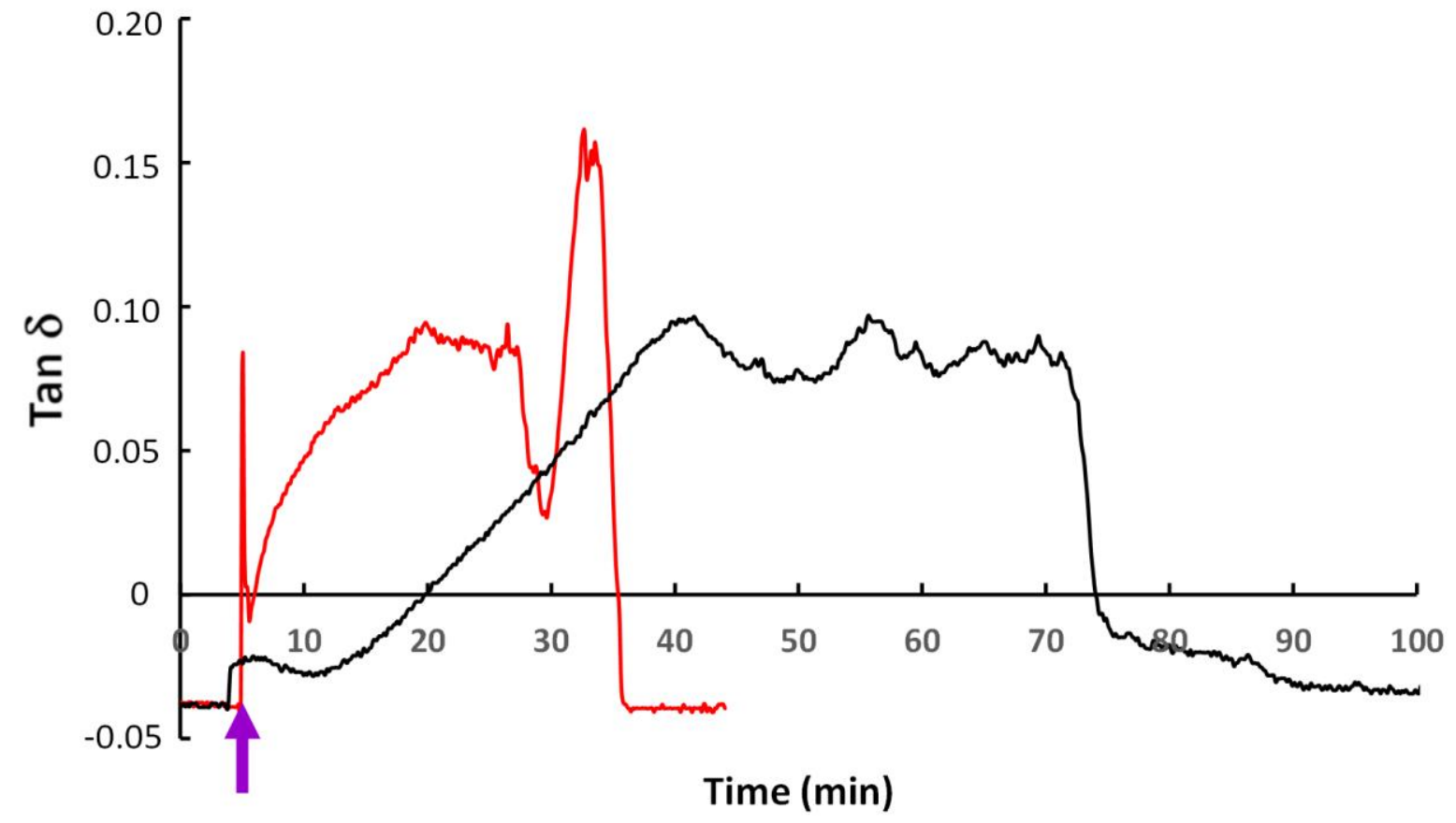


Figure 5. SEM observation of a polished cross-section of the HBS- 0 reference (a) and the $8 / 50$ (b), 16/100 (c) and 24/150 (d) CPC composites, using a 5 wt.\% aqueous $\mathrm{Na}_{2} \mathrm{HPO}_{4}$ solution as a liquid phase, after a setting time of 1 week. Magnification: $\times 1500$.
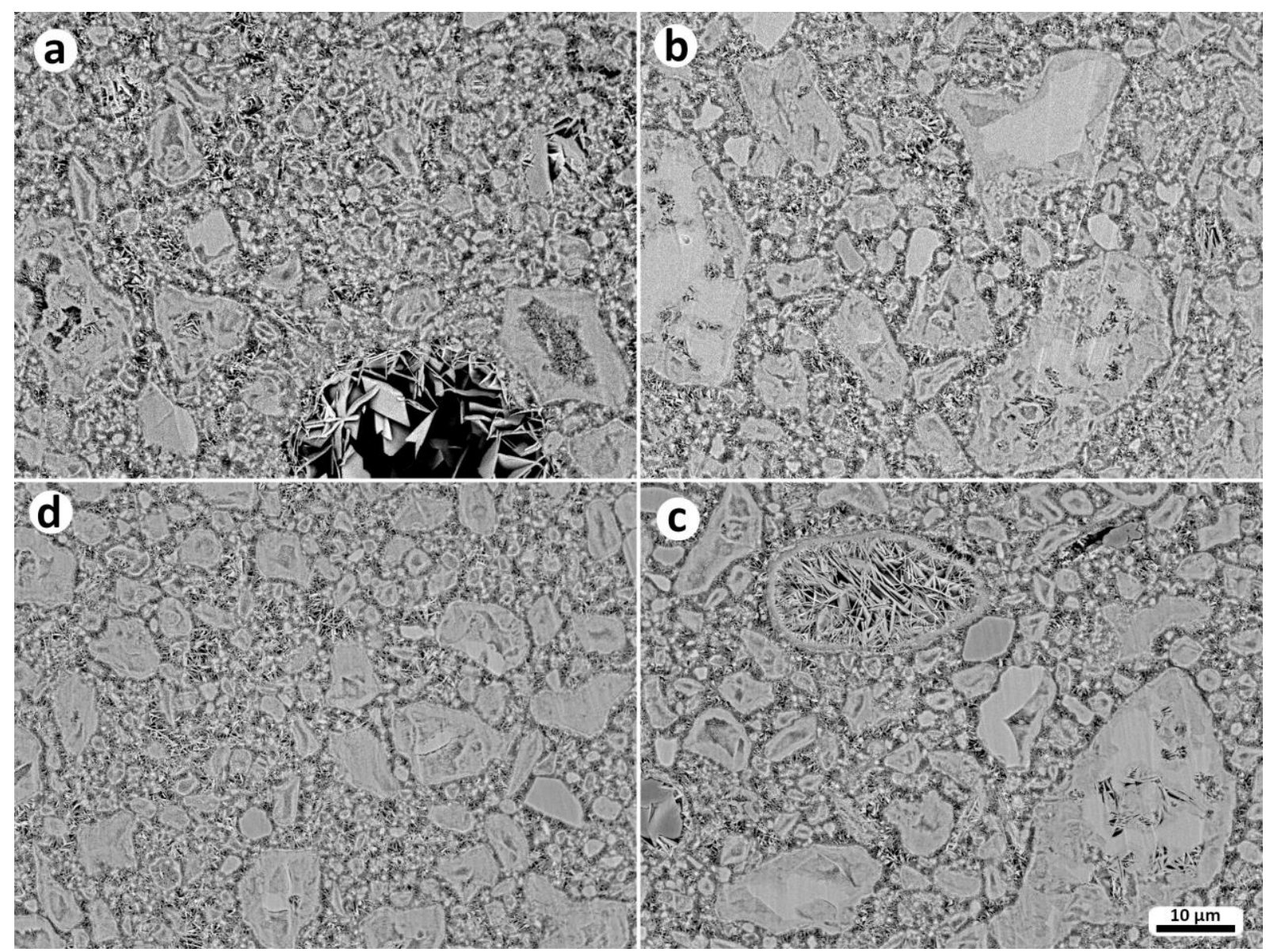
Figure 6. SEM observation of a polished cross-section of the HBS-0 reference (a) and the 8/50 (b), 16/100 (c) and 24/150 (d) CPC composites, using a 5 wt.\% aqueous $\mathrm{Na}_{2} \mathrm{HPO}_{4}$ solution as a liquid phase, after a setting time of 1 week. Magnification: $\times 5000$.
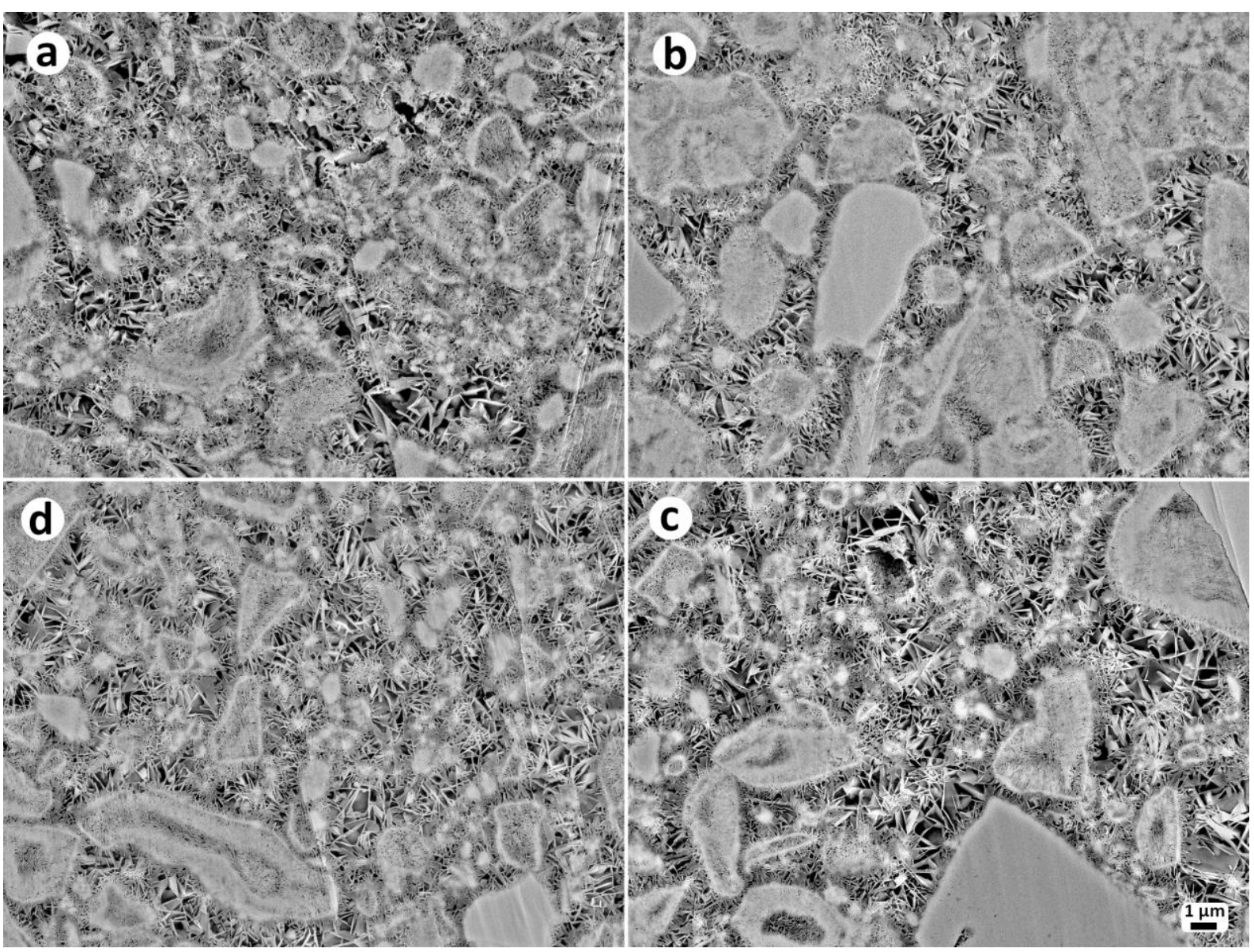
Figure 7. SEM observation of a polished cross-section of the HBS-0 reference (a) and the 16/100 (b), 24/150 (c) and 40/250 (d) CPC composites, using a 2 wt.\% aqueous $\mathrm{Na}_{2} \mathrm{HPO}_{4}$ solution as a liquid phase, after a setting time of 1 week. Magnification: $\times 1500$.
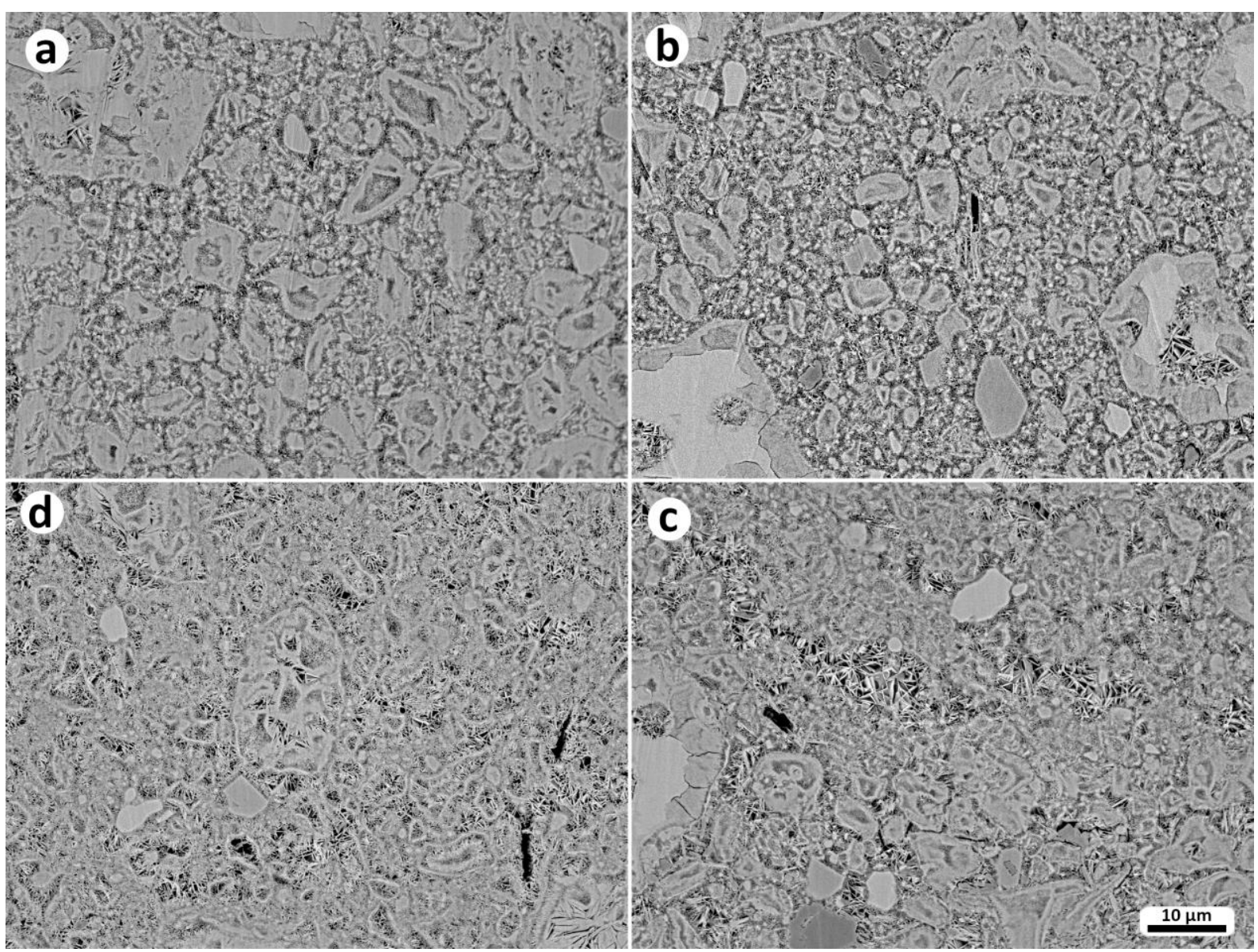
Figure 8. SEM observation of a polished cross-section of the HBS-0 reference (a) and the 16/100 (b), 24/150 (c) and 40/250 (d) CPC composites, using a 2 wt.\% aqueous $\mathrm{Na}_{2} \mathrm{HPO}_{4}$ solution as a liquid phase, after a setting time of 1 week. Magnification: $\times 5000$.

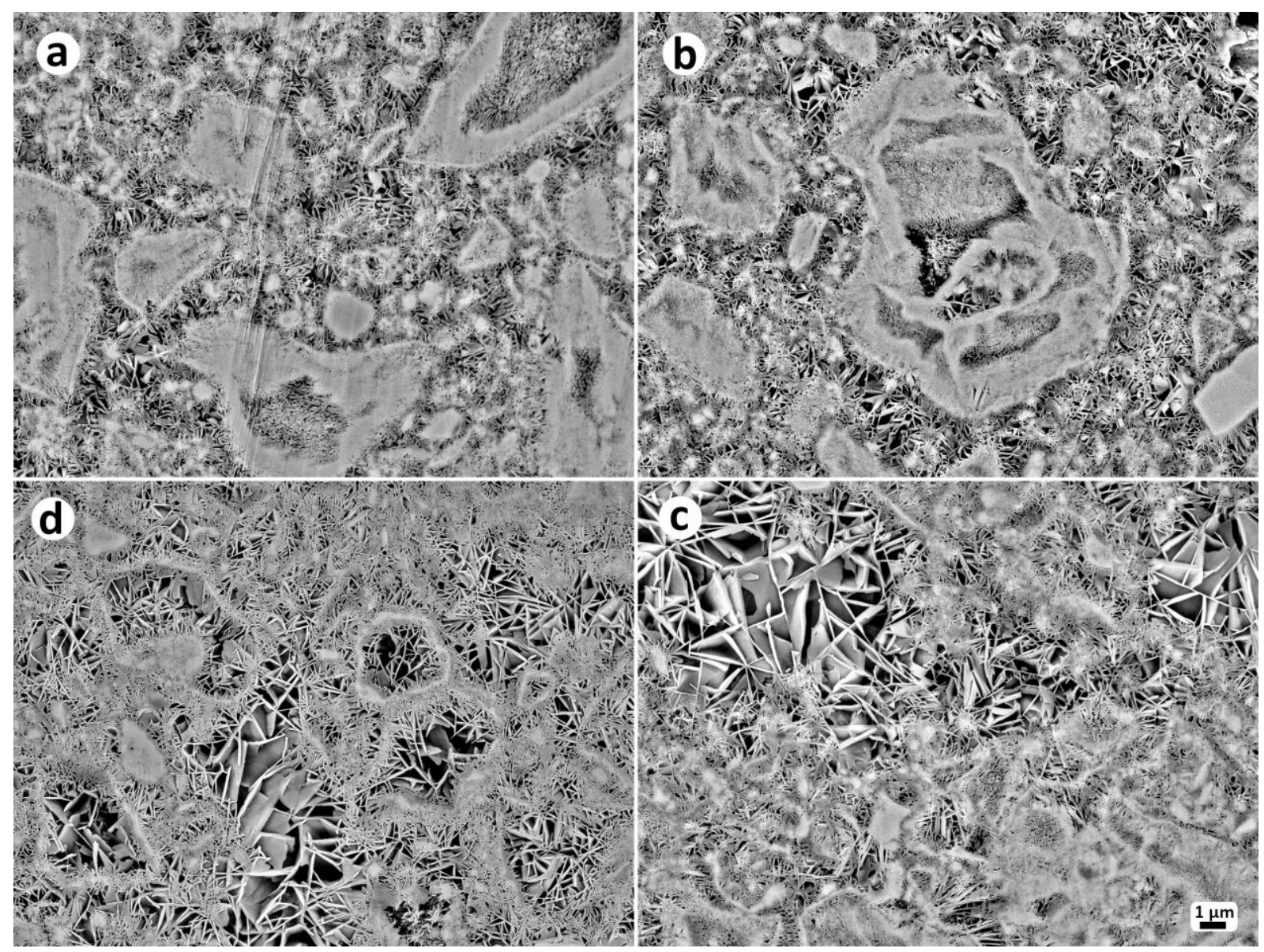


Figure 9. SEM observation of a fracture plane of CPC composites (liquid phase: 2 wt.\% aqueous $\mathrm{Na}_{2} \mathrm{HPO}_{4}$ solution) after EDTA-mediated removal of the inorganic component. Right view: 24/150 CPC composite (magnification: $\times 1000$ ). Left views: 40/250 CPC composite (magnification: $\times 1000$ (top); $\times 250$ (bottom)).

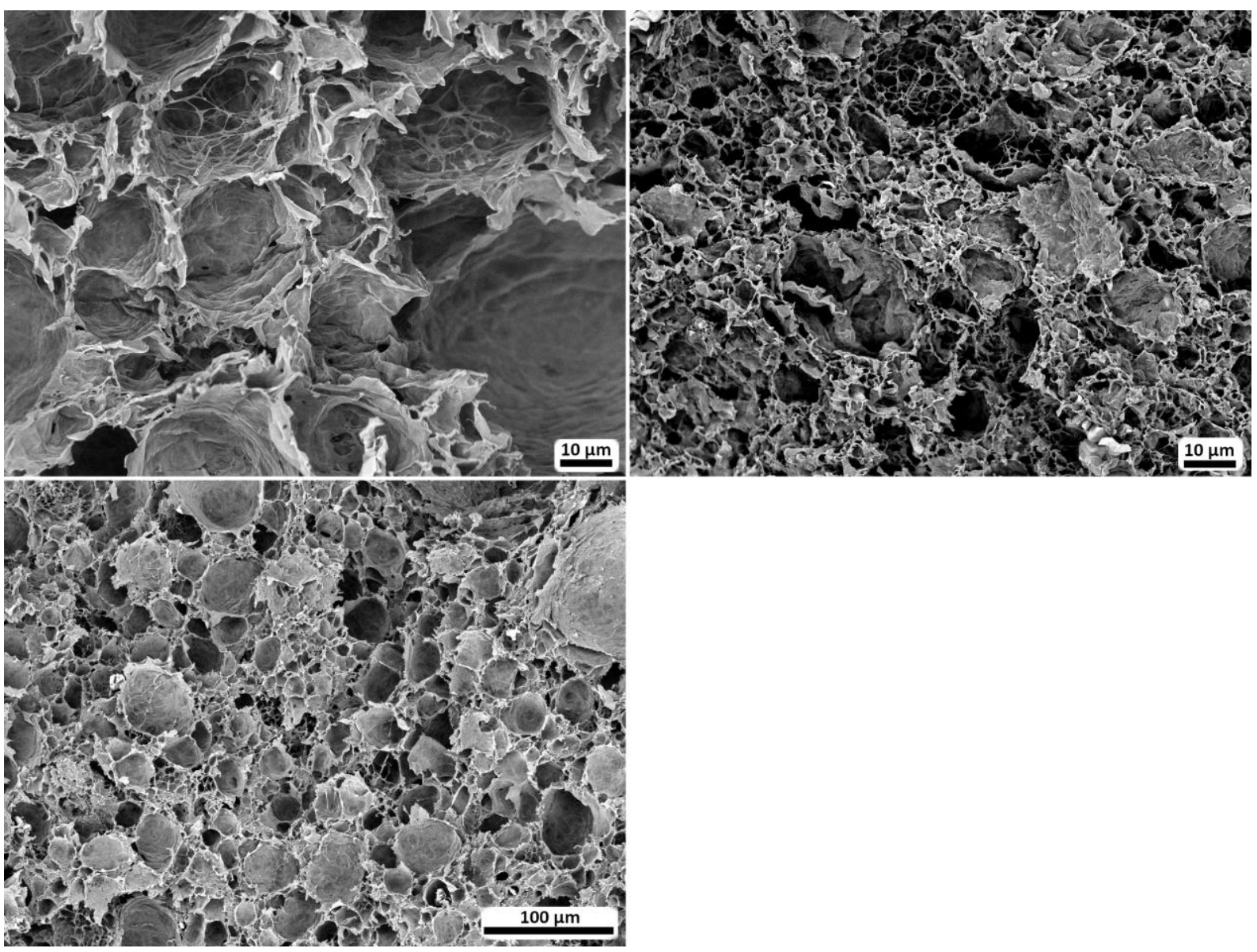


Table 1. Characteristic parameters resulting from the monitoring of the setting reaction of the HBS-0 reference cement and the corresponding composites at $37^{\circ} \mathrm{C}$, using high frequency impedance measurements.

\begin{tabular}{|c|c|c|c|c|}
\hline \multicolumn{5}{|c|}{ Liquid phase: 5 wt. $\% \mathrm{Na}_{2} \mathrm{HPO}_{4}$} \\
\hline DGL/PEG- & $\mathrm{t}_{1}\left(\varepsilon^{\prime}\right)(\min )$ & $\mathrm{t}_{1}\left(\varepsilon^{\prime \prime}\right)(\mathrm{min})$ & $\mathrm{t}_{2}\left(\varepsilon^{\prime}\right)(\min )$ & $\mathrm{t}_{2}\left(\varepsilon^{\prime \prime}\right)(\mathrm{min})$ \\
\hline \multicolumn{5}{|l|}{ NHS (mg/mL) } \\
\hline $0 / 0$ & $20 \pm 1$ & $15 \pm 1$ & $38 \pm 2$ & $39 \pm 2$ \\
\hline $16 / 100$ & $30 \pm 2$ & $23 \pm 1$ & $66 \pm 3$ & $70 \pm 3$ \\
\hline $24 / 150$ & $30 \pm 2$ & $19 \pm 1$ & $93 \pm 2$ & $107 \pm 4$ \\
\hline \multicolumn{5}{|c|}{ Liquid phase: 2 wt.\% $\mathrm{Na}_{2} \mathrm{HPO}_{4}$} \\
\hline DGL/PEG- & $\mathrm{t}_{1}\left(\varepsilon^{\prime}\right)(\mathrm{min})$ & $\mathrm{t}_{1}\left(\varepsilon^{\prime \prime}\right)(\mathrm{min})$ & $\mathrm{t}_{2}\left(\varepsilon^{\prime}\right)(\min )$ & $\mathrm{t}_{2}(\varepsilon, ')(\mathrm{min})$ \\
\hline \multicolumn{5}{|l|}{ NHS (mg/mL) } \\
\hline $0 / 0$ & $60 \pm 2$ & $60 \pm 2$ & $95 \pm 2$ & $105 \pm 3$ \\
\hline $16 / 100$ & $160 \pm 6$ & $130 \pm 5$ & $260 \pm 10$ & $300 \pm 4$ \\
\hline $24 / 150$ & $295 \pm 6$ & $275 \pm 8$ & $430 \pm 10$ & $465 \pm 14$ \\
\hline $40 / 250$ & $375 \pm 8$ & $375 \pm 5$ & $520 \pm 9$ & $590 \pm 5$ \\
\hline
\end{tabular}


Table 2. Time elapsed for characteristic events of the variation of the tangent of the phase angle, for the DGL / PEG-NHS mixtures in 2 or 5 wt.\% aqueous $\mathrm{Na}_{2} \mathrm{HPO}_{4}$. * indicates a statistically significant difference between hydrogels for a given disodium phosphate concentration (p<0.05). ${ }^{\$}$ indicates a significant difference between the DGL/PEG-NHS 8/50 and 16/100 hydrogels formed in $5 \mathrm{wt} . \% \mathrm{Na}_{2} \mathrm{HPO}_{4}(\mathrm{p}<0.05)$. For hydrogels prepared in $2 \mathrm{wt} . \% \mathrm{Na}_{2} \mathrm{HPO}_{4}$, \& indicates a significant difference between the DGL/PEG-NHS 8/50 and 40/250 concentrations, ${ }^{\circledR}$ between $16 / 100$ and $24 / 150$, and ${ }^{\varphi}$ between $24 / 150$ and 40/250, with a confidence level of $\mathrm{p}<0.05$.

\begin{tabular}{|c|c|c|c|c|c|c|c|}
\hline Liquid phase & \multicolumn{3}{|c|}{5 wt. \% $\mathrm{Na}_{2} \mathrm{HPO}_{4}$} & \multicolumn{3}{c|}{2 wt. $\% \mathrm{Na}_{2} \mathrm{HPO}_{4}$} \\
\hline $\begin{array}{c}\text { DGL/PEG- } \\
\text { NHS } \\
(\mathrm{mg} \mathrm{mL})^{-1}\end{array}$ & $8 / 50$ & $16 / 100$ & $24 / 150$ & $8 / 50$ & $16 / 100$ & $24 / 150$ & $40 / 250$ \\
\hline $\begin{array}{l}\text { Time elapsed } \\
\text { at the } \\
\text { beginning of } \\
\text { the variation } \\
\text { of the tan } \delta \\
\text { (seconds) }\end{array}$ & $96 \pm 37^{\$}$ & $52 \pm 2$ & $60 \pm 3$ & $88 \pm 13^{*}$ & $53 \pm 1$ & $62 \pm 9$ & $57 \pm 4$ \\
\hline $\begin{array}{l}\text { Time elapsed } \\
\text { at the end of } \\
\text { the variation } \\
\text { of the tan } \delta \\
\text { (seconds) }\end{array}$ & $403 \pm 128$ & $857 \pm 212^{*}$ & $536 \pm 14$ & $765 \pm 55^{\&}$ & $473 \pm 187^{\Theta}$ & $841 \pm 282^{\varphi}$ & $306 \pm 64$ \\
\hline
\end{tabular}


Table 3. Time elapsed for characteristic events of the variation of the $\tan \delta$, for the CPC composites compared to the CPC references, using a 2 or 5 wt.\% aqueous $\mathrm{Na}_{2} \mathrm{HPO}_{4}$ solution. * indicates a statistically significant difference between hydrogels for a given disodium phosphate concentration $(\mathrm{p}<0.05) .{ }^{\$}$ indicates a significant difference between the DGL/PEG-NHS 8/50 and 16/100 hydrogels formed in 5wt.\% $\mathrm{Na}_{2} \mathrm{HPO}_{4}(\mathrm{p}<0.05)$. For hydrogels prepared in $2 \mathrm{wt} . \%$ $\mathrm{Na}_{2} \mathrm{HPO}_{4},{ }^{\&}$ indicates a significant difference between the DGL/PEG-NHS 8/50 and 40/250 concentrations, @ between 16/100 and 24/150, and ${ }^{\varphi}$ between $24 / 150$ and 40/250, with a confidence level of $\mathrm{p}<0.05$.

\begin{tabular}{|c|c|c|c|c|c|c|c|c|c|}
\hline Liquid phase & \multicolumn{3}{|c|}{$5 \mathrm{wt} \% \mathrm{Na}_{2} \mathrm{HPO}_{4}$} & \multicolumn{5}{c|}{2 wt.\% $\mathrm{Na}_{2} \mathrm{HPO}_{4}$} \\
\hline $\begin{array}{c}\text { DGL/PEG- } \\
\text { NHS } \\
\left.(\mathrm{mg} \mathrm{mL})^{-1}\right)\end{array}$ & $0 / 0$ & $8 / 50$ & $16 / 100$ & $24 / 150$ & $0 / 0$ & $8 / 50$ & $16 / 100$ & $24 / 150$ & $40 / 250$ \\
\hline $\begin{array}{l}\text { Time elapsed } \\
\text { at the } \\
\text { beginning of } \\
\text { the increase } \\
\text { of the tan } \delta \\
\text { (seconds) }\end{array}$ & $121 \pm 6$ & $134 \pm 1$ & $624 \pm 5^{*}$ & $582 \pm 28^{\#}$ & $1112 \pm 103^{*}$ & $112 \pm 65^{\S}$ & $291 \pm 42$ & $178 \pm 35$ & $174 \pm 8$ \\
\hline $\begin{array}{l}\text { Time elapsed } \\
\text { at end of } \\
\text { the increase } \\
\text { of the tan } \delta \\
\text { (seconds) }\end{array}$ & $1019 \pm 93$ & $1096 \pm 102$ & $2474 \pm 21^{*}$ & $2110 \pm 173^{\#}$ & $2002 \pm 241$ & $1334 \pm 806$ & $1273 \pm 326$ & $891 \pm 144^{\&}$ & $1176 \pm 88$ \\
\hline $\begin{array}{l}\text { Time elapsed } \\
\text { for the tan } \delta \\
\text { (seconds) to } \\
\text { return to the } \\
\text { baseline }\end{array}$ & $1844 \pm 176$ & $1963 \pm 52$ & $3920 \pm 125^{*}$ & $4256 \pm 93^{\#}$ & $2864 \pm 479$ & $2265 \pm 682$ & $2628 \pm 572$ & $2836 \pm 323$ & $3340 \pm 131$ \\
\hline
\end{tabular}


Table 4. General properties of the different CPC composites and related HBS-0 references : injectability, compressive strength and qualitative assessment of the organic component [only for the CPC composites].

\begin{tabular}{|c|c|c|c|c|c|}
\hline & Liquid phase & \multicolumn{4}{|c|}{2 wt. $\% \mathrm{Na}_{2} \mathrm{HPO}_{4}$} \\
\hline & $\begin{array}{c}\text { DGL/PEG-NHS } \\
\left(\mathrm{mg} \mathrm{mL}^{-1}\right)\end{array}$ & $8 / 50$ & $16 / 100$ & $24 / 150$ & $40 / 250$ \\
\hline \multirow{2}{*}{$\begin{array}{l}\text { Decalcified } \\
\text { samples }\end{array}$} & $\begin{array}{l}\text { Presence of an } \\
\text { organic residue }\end{array}$ & Yes & Yes & Yes & Yes \\
\hline & $\begin{array}{l}\text { Behavior of the } \\
\text { residue in water }\end{array}$ & $\begin{array}{l}\text { Shapeless, } \\
\text { non self } \\
\text { supporting }\end{array}$ & $\begin{array}{l}\text { Cylinder- } \\
\text { shape, non } \\
\text { self } \\
\text { supporting } \\
\end{array}$ & $\begin{array}{l}\text { Cylinder- } \\
\text { shape, self } \\
\text { supporting }\end{array}$ & $\begin{array}{l}\text { Expanded } \\
\text { cylinder- } \\
\text { shape, self } \\
\text { supporting }\end{array}$ \\
\hline \multirow{2}{*}{\multicolumn{2}{|c|}{ Compressive strength (MPa) }} & $14.96 \pm 1.18^{\#}$ & $14.32 \pm 1.66^{\#}$ & $19.62 \pm 1.19^{\#}$ & $15.16 \pm 1.78^{\#}$ \\
\hline & & \multicolumn{4}{|c|}{$12.68 \pm 2.25$ for HBS-0 } \\
\hline \multicolumn{2}{|c|}{$\begin{array}{l}\text { Amount of cement paste extruded after } 15 \\
\text { minutes (applied extrusion force in } \mathrm{N} \text { ) }\end{array}$} & $\begin{array}{l}64 \% \pm 1 \\
(24 \pm 4)\end{array}$ & $\begin{array}{l}81 \% \pm 3 \\
(12 \pm 3)\end{array}$ & $\begin{array}{l}89 \% \pm 1 \\
(19 \pm 2) \\
\end{array}$ & $\begin{array}{c}95 \% \pm 1 \\
(2 \pm 1) \\
\end{array}$ \\
\hline \multicolumn{2}{|c|}{$\begin{array}{l}\text { Amount of cement paste extruded after } 15 \\
\text { minutes (applied extrusion force in } \mathrm{N} \text { ) }\end{array}$} & \multicolumn{4}{|c|}{$89 \% \pm 1(2 \pm 0.3)$ for HBS-0 } \\
\hline & Liquid phase & \multicolumn{4}{|c|}{5 wt. $\% \mathrm{Na}_{2} \mathrm{HPO}_{4}$} \\
\hline & $\begin{array}{l}\text { DGL/PEG-NHS } \\
\left(\mathrm{mg} \mathrm{mL}^{-1}\right)\end{array}$ & & & $16 / 100$ & $24 / 150$ \\
\hline \multirow{2}{*}{$\begin{array}{l}\text { Decalcified } \\
\text { samples }\end{array}$} & $\begin{array}{l}\text { Presence of an } \\
\text { organic residue }\end{array}$ & & & Yes & Yes \\
\hline & $\begin{array}{l}\text { Behavior of the } \\
\text { residue in water }\end{array}$ & & & $\begin{array}{c}\text { Shapeless, } \\
\text { non self } \\
\text { supporting }\end{array}$ & $\begin{array}{l}\text { Cylinder- } \\
\text { shape, non } \\
\text { self } \\
\text { supporting }\end{array}$ \\
\hline \multirow{2}{*}{\multicolumn{2}{|c|}{ Compressive strength (MPa) }} & 15.2 & 1.27 & $14.54 \pm 0.78^{*}$ & $16.86 \pm 2.82 *$ \\
\hline & & \multicolumn{4}{|c|}{$\begin{array}{c}18.79 \pm 2.41 \text { for HBS-0 } \\
13.18 \pm 2.26 \text { for HBS }\end{array}$} \\
\hline \multicolumn{2}{|c|}{$\begin{array}{l}\text { Amount of cement paste extruded after } 15 \\
\text { minutes (applied extrusion force in } \mathrm{N} \text { ) }\end{array}$} & \multicolumn{2}{|c|}{$\begin{array}{l}90 \% \\
(7 \pm 1)\end{array}$} & $\begin{array}{c}95 \% \\
(4 \pm 1) \\
\end{array}$ & $\begin{array}{c}85 \% \\
(41 \pm 3)\end{array}$ \\
\hline \multicolumn{2}{|c|}{$\begin{array}{c}\text { Amount of cement paste extruded after } 15 \\
\text { minutes (applied extrusion force in } \mathrm{N} \text { ) }\end{array}$} & \multicolumn{4}{|c|}{$\begin{array}{c}74 \% \pm 1(12 \pm 1) \text { for HBS-0 } \\
93 \% \pm 1(17 \pm 2) \text { for HBS }\end{array}$} \\
\hline
\end{tabular}

$* 16 / 100$ and $24 / 250$ are statistically different, with $\mathrm{p}$ values in $t$-test of 0.002 and 0.005 , respectively. \#The $8 / 50,16 / 100,40 / 250$ formulations were statistically significant different from the $24 / 150$ formulation ( $\mathrm{p}$ values $<0.05$ ). 


\section{Supporting Information}
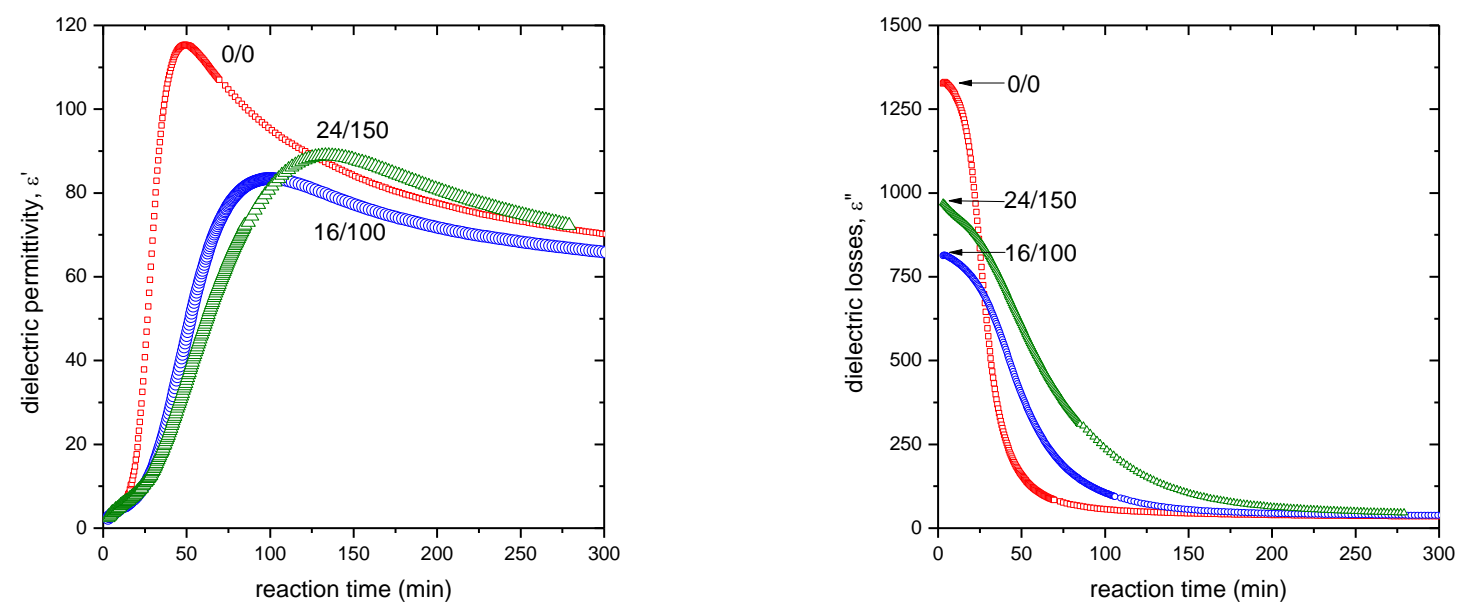

Figure S1. Variation of dielectric permittivity, $\varepsilon^{\prime}\left(\right.$ left), and dielectric losses, $\varepsilon^{\prime \prime}$ (right) versus reaction time for the HBS reference (0/0) and the CPC composites loaded with DGL/PEGNHS: respectively, $16 \mathrm{mg} \mathrm{mL}^{-1} / 100 \mathrm{mg} \mathrm{mL}^{-1}$ and $24 \mathrm{mg} \mathrm{mL}^{-1} / 150 \mathrm{mg} \mathrm{mL}^{-1}$, with a $5 \mathrm{wt} . \%$ $\mathrm{Na}_{2} \mathrm{HPO}_{4}$ liquid phase. Frequency: $10 \mathrm{MHz}, 37^{\circ} \mathrm{C}$. 

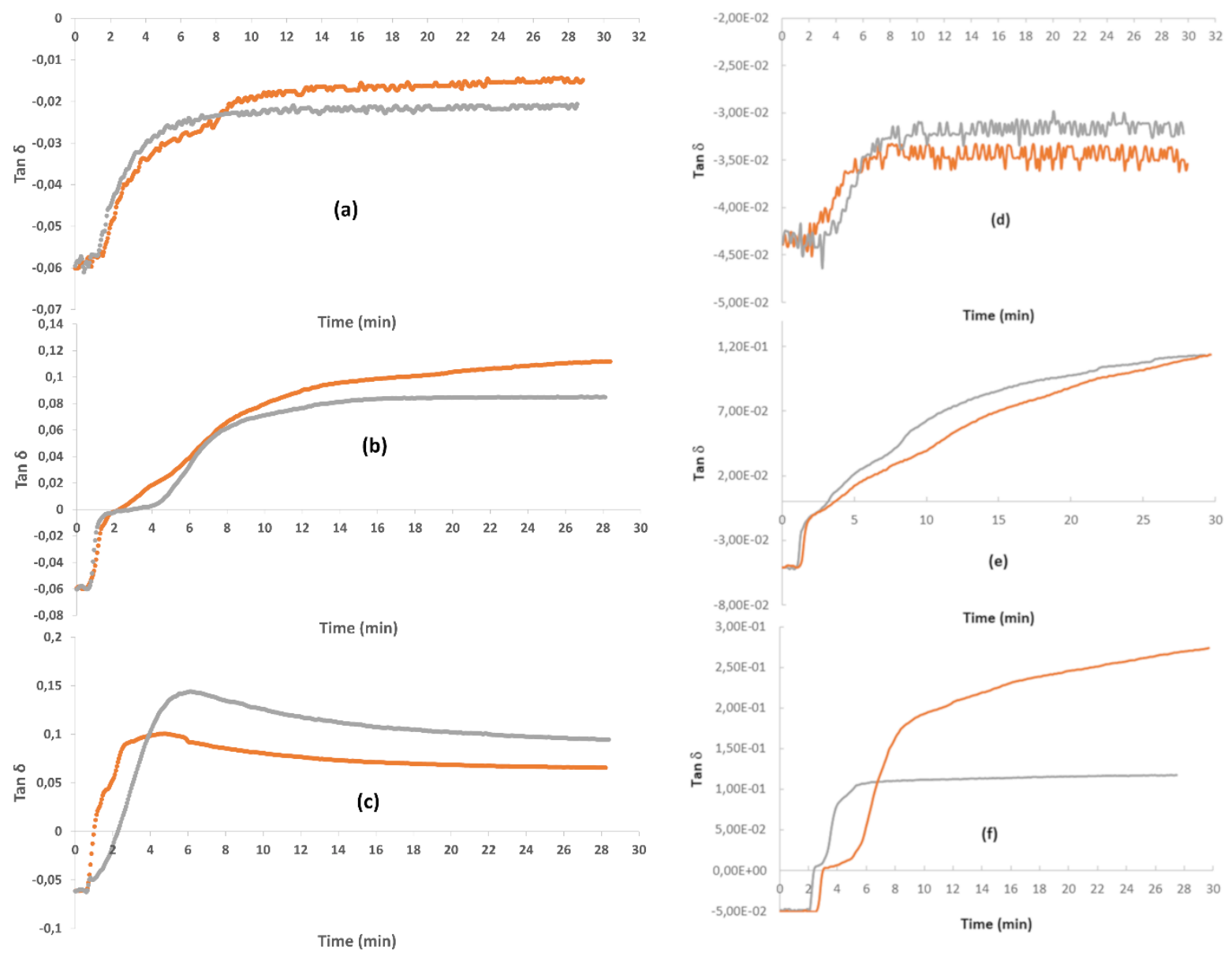

Figure S2. Variation of $\tan \delta$ versus time measured by DMA on a DGL mixed with PEG-NHS. The curves correspond to the repetition of two different experiments. Data for (a) DGL (8 mg $\left.\mathrm{mL}^{-1}\right) /$ PEG-NHS (50 mg mL $\left.\mathrm{m}^{-1}\right)$; (b) DGL (24 mg mL $\left.\mathrm{m}^{-1}\right) /$ PEG-NHS (150 mg mL $\left.{ }^{-1}\right)$; (c) DGL (40 mg mL ${ }^{-1}$ ) / PEG-NHS (250 mg mL $\mathrm{mL}^{-1}$ ), in 2 wt.\% aqueous $\mathrm{Na}_{2} \mathrm{HPO}_{4}$. Data for (d) DGL (8 mg mL $\left.{ }^{-1}\right) /$ PEG-NHS (50 mg mL $\left.{ }^{-1}\right)$; (e) DGL $\left(16 \mathrm{mg} \mathrm{mL}^{-1}\right) /$ PEG-NHS (100 mg mL $\left.{ }^{-1}\right)$; (f) DGL (24 mg mL $\left.{ }^{-1}\right) /$ PEG-NHS (150 $\left.\mathrm{mg} \mathrm{mL}^{-1}\right)$, in 5 wt.\% aqueous $\mathrm{Na}_{2} \mathrm{HPO}_{4}$. 


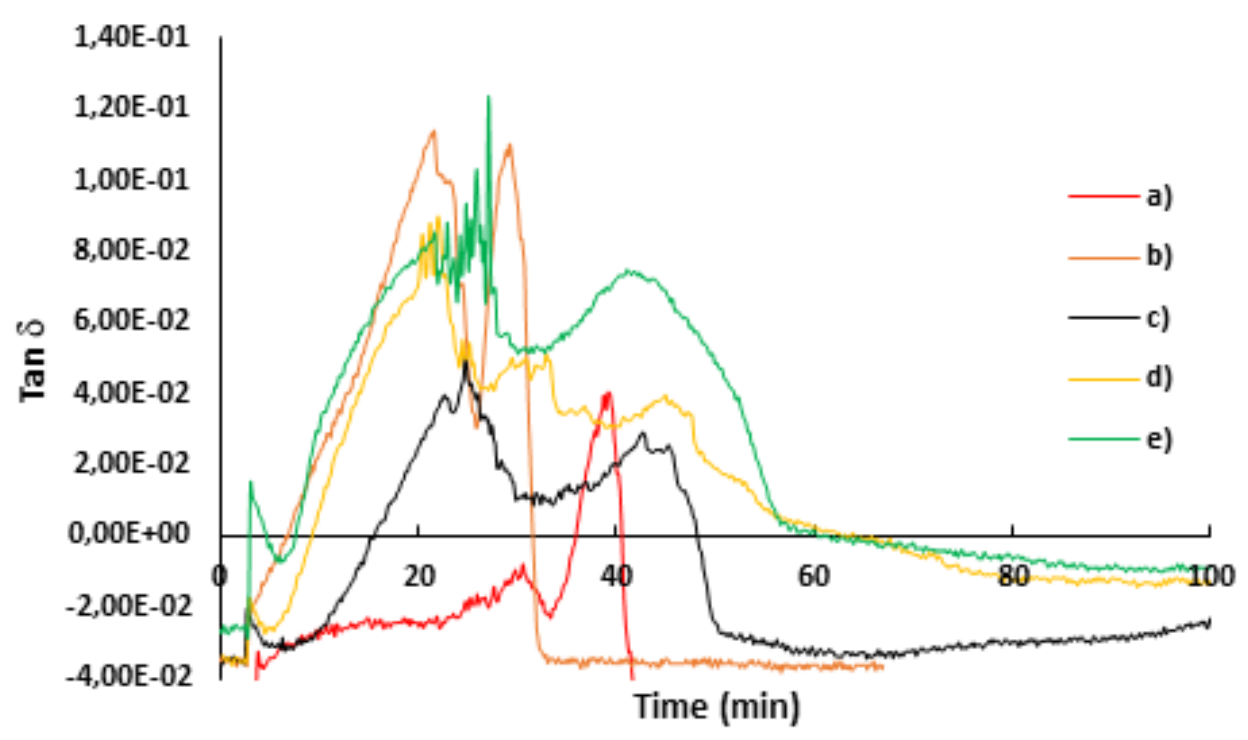

Figure S3. Variation of $\tan \delta$ versus time measured by DMA on the (a) $0 / 0$, (b) $8 / 50$, (c) $16 / 100$, (d) 24/150 and (e) 40/250 CPC composites, in 2 wt.\% aqueous $\mathrm{Na}_{2} \mathrm{HPO}_{4}$.

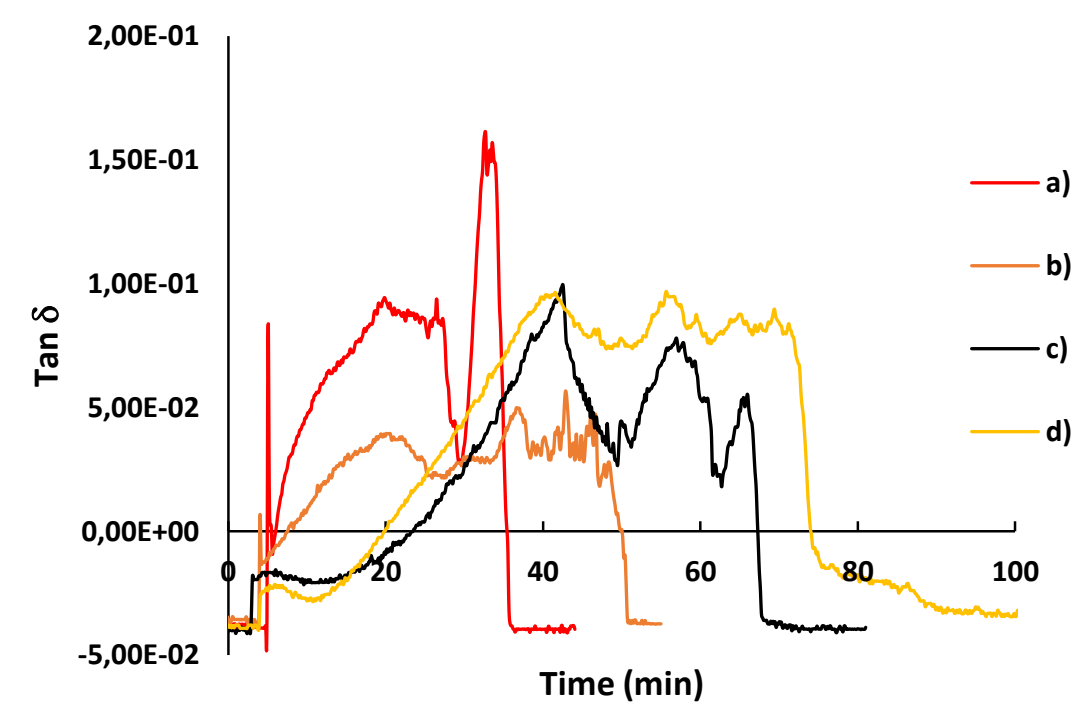

Figure S4. Variation of $\tan \delta$ versus time measured by DMA on the (a) $0 / 0$, (b) $8 / 50$, (c) $16 / 100$ and (d) 24/150 CPC composites, in 5 wt.\% aqueous $\mathrm{Na}_{2} \mathrm{HPO}_{4}$. 

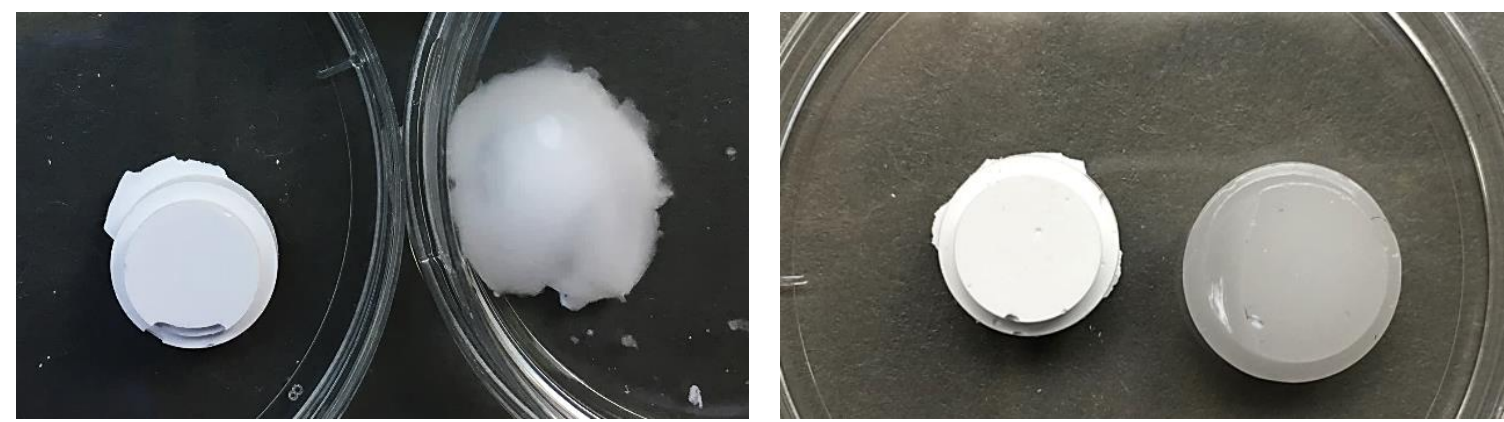

Figure S5. View of the hardened CPC composites, before (left) and after decalcification : (a) example of a composite for which the hydrogel network was not self supporting [16/100 CPC composite in 5 wt.\% aqueous $\left.\mathrm{Na}_{2} \mathrm{HPO}_{4}\right]$; (b) example of a composite for which the hydrogel network was self supporting [40/250 CPC composite in 2 wt.\% aqueous $\mathrm{Na}_{2} \mathrm{HPO}_{4}$, extruded 5 minutes after preparation of the paste] - in this case the shape of the cement block was retained with a size expansion due to a swelling phenomenon.
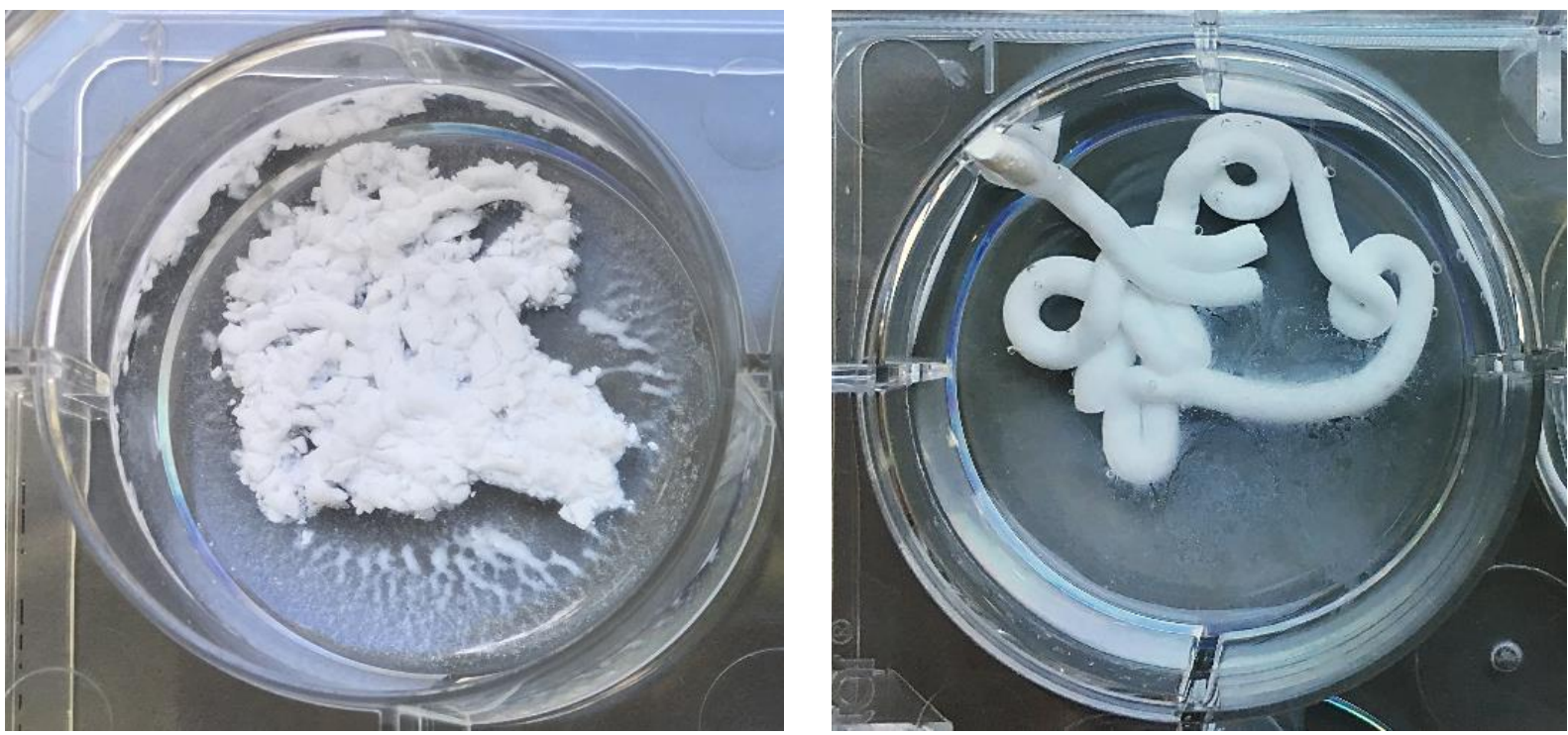

Figure S6. Qualitative assessment of the cohesion of the CPC samples : (a) example of the noncohesive HBS-0 reference [in 2 wt.\% aqueous $\mathrm{Na}_{2} \mathrm{HPO}_{4}$, extruded 5 minutes after preparation of the paste] showing a disaggregation of the paste after injection in a $0.9 \mathrm{wt} \% \mathrm{NaCl}$ solution ; (b) example of a cohesive composite [40/250 CPC composite in 2 wt.\% aqueous $\mathrm{Na}_{2} \mathrm{HPO}_{4}$, 
extruded 5 minutes after preparation of the paste]. 